\title{
From engineering hydrology to Earth system science: milestones in the transformation of hydrologic science
}

\author{
Murugesu Sivapalan ${ }^{1, *}$ \\ ${ }^{1}$ Department of Civil and Environmental Engineering, Department of Geography and Geographic Information Science, \\ University of Illinois at Urbana-Champaign, Urbana, Illinois 61801, USA \\ * Invited contribution by Murugesu Sivapalan, recipient of the EGU Alfred Wegener Medal \& Honorary Membership 2017.
}

Correspondence: Murugesu Sivapalan (sivapala@illinois.edu)

Received: 13 November 2017 - Discussion started: 15 November 2017

Revised: 2 February 2018 - Accepted: 5 February 2018 - Published: 7 March 2018

\begin{abstract}
Hydrology has undergone almost transformative changes over the past 50 years. Huge strides have been made in the transition from early empirical approaches to rigorous approaches based on the fluid mechanics of water movement on and below the land surface. However, progress has been hampered by problems posed by the presence of heterogeneity, including subsurface heterogeneity present at all scales. The inability to measure or map the heterogeneity everywhere prevented the development of balance equations and associated closure relations at the scales of interest, and has led to the virtual impasse we are presently in, in terms of development of physically based models needed for hydrologic predictions. An alternative to the mapping of heterogeneity everywhere is a new Earth system science view, which sees the heterogeneity as the end result of co-evolutionary hydrological, geomorphological, ecological, and pedological processes, each operating at a different rate, which help to shape the landscapes that we find in nature, including the heterogeneity that we do not readily see. The expectation is that instead of specifying exact details of the heterogeneity in our models, we can replace it (without loss of information) with the ecosystem function that they perform. Guided by this new Earth system science perspective, development of hydrologic science is now addressing new questions using novel holistic co-evolutionary approaches as opposed to the physical, fluid mechanics based reductionist approaches that we inherited from the recent past. In the emergent Anthropocene, the co-evolutionary view has expanded further to involve interactions and feedbacks with human-social processes as well. In this paper, I present my own perspective of key milestones in the transformation of hydrologic science from engineering
\end{abstract}

hydrology to Earth system science, drawn from the work of several students and colleagues of mine, and discuss their implication for hydrologic observations, theory development, and predictions.

\footnotetext{
எப்பொருள் யார்யார்வாய்க் கேட்பினும் அப்பொருள் மெய்ப்பொருள் காண்ப தறிவு

In whatever matter and from whomever heard, Wisdom will witness its true meaning.

Thirukkural, Verse 423 (Thiruvalluvar, c. 132 BC).

Translated by GU Pope, 1886
}

\section{Introduction}

Hydrology has undergone an almost complete transformation over the past century, from its empirical origins in the early 20th century, to become a fully fledged and key component of Earth system science by the early 21 st century (Chow, 1964; Sivapalan and Blöschl, 2017). In this paper, I use the precious opportunity given to me by the European Geosciences Union, as part of my 2017 Alfred Wegener Lecture, to reflect on the evolution of the field, as both interested observer and participant, as well as a student of hydrology for the past 50 years.

I hope that the issues I raise, and the trends and milestones I recognize in the evolution of the science that I recount here, resonate with the experiences of many readers, even if they might not fully agree with my interpretations of the events and/or their antecedents. This is one person's 
view of the vast landscape that hydrologists have collectively traversed, so perspectives abound. This is also not the first commentary of its kind: indeed, my thinking during my formative years was guided by the writings of Vit Klemeš and James Dooge, including their classic papers (Klemeš, 1983, 1986; Dooge, 1986). Their writings have provided unique perspectives on the field of hydrological science and its evolution over the past several decades. I hope that by re-telling this story through the admittedly narrow prism of my own observations and experience as a catchment hydrologist, I might be able to provide fresh impetus to early career hydrologists and new entrants to the field, and encourage them to reflect on and chart the course of their own future education and research.

\section{Engineering hydrology: legacies of the past to new beginnings}

My earliest introduction to hydrology and later work experience are probably similar to those of many hydrologists of my generation, i.e., 1970s vintage, especially those coming out of engineering schools. Going back in time, 50 years ago hydrology was mostly non-existent as a subject of study in many engineering schools (certainly not in Sri Lanka where I grew up). Most water-related education was then centered on fluid mechanics, e.g., open channel or river hydraulics, with a strong focus on applications to irrigation or hydraulic engineering. In 1972 when I walked into a hydrology class at the then University of Ceylon (later Sri Lanka), it was taught by a recent convert from fluid mechanics, who had subsequently received specialist training in hydrology.

Hydrology education in those days covered three key topics: infiltration and runoff generation (e.g., SCS curve number method), the unit hydrograph method to runoff routing, and the flood frequency curve approach to flood estimation (Linsley et al., 1958). The focus of the training was on estimation, especially flood estimation (event scale, recipe style) and the approach was lumped and empirical. Compared to now, these involved relatively much simpler problems, framed directly at the catchment scale, and formed the bread and butter of engineering hydrology, not just in Sri Lanka, but all over the world. The three building blocks of engineering hydrology were indeed legacies of three different previous eras in the growth of the field up until the 1970s (Sivapalan and Blöschl, 2017): empirical era (flood frequency analysis), rationalization era (SCS curve number method) and systems era (unit hydrograph method). These estimation methods remain relevant to this day, very much the core of engineering hydrology, judging by the popularity of advanced textbooks such as Chow et al. (1988), which is still widely used for the training of hydrologists in engineering schools.

For some of us who were then being trained in mechanics - solid mechanics, fluid mechanics, soil mechanics, etc.
- the hydrology being taught and practiced using traditional estimation methods might have appeared strange and even mysterious. In the early days, I remember being frustrated that I could not make much physical sense of the cookbook treatment of the hydrologic estimation procedures, being unable to connect it to fundamental fluid mechanics principles. However, there was also wide appreciation for these otherwise simpler methods that efficiently solved practical problems of that day and age. In fact, even today's standard engineering practice would still be impossible without these simpler approaches.

There was also a profound fascination. How is it possible that something so inherently complex, as hydrology is, still comes out so simple (apparently) in practice? Over the years, there was a grudging realization that perhaps hydrology is more than about fluid mechanics (Yevjevich, 1968). Indeed, the search for simplicity in amongst the enormous mechanistic complexity has been a constant theme in hydrologic research over the last 50 years (Rodriguez-Iturbe and Valdes, 1979; Sivapalan, 2003; Savenije, 2017). The answer to this question, we now know in hindsight, is tied up with the issue of scale (both space and time) and the objects of our study, catchments, being not simple physical (or mechanical) objects but complex ecosystems (Gaál et al., 2012), consisting of component parts that have co-evolved together over time and are thus co-dependent (Dooge, 1986; Davies, 1992). I return to this theme throughout this paper.

\section{Spatial heterogeneity and scale: promise of Newtonian mechanics}

While the simple black-box methods of engineering hydrology did solve practical problems efficiently, they had limitations when extrapolating to circumstances beyond those from which they were developed. For example, what is the effect of antecedent wetness on runoff generation (Mein and Larson, 1973)? How does one account for the nonlinearity of catchment response to the size of rainfall events (Minshall, 1960)? How does one deal with the climatic and geologic controls when extrapolating flood frequencies to ungauged catchments (IACWD, 1982)? Also, new and more complex problems were emerging, such as the effects of land use changes on streamflows and flooding, and increased concerns about river water quality, which demanded application of more process understanding (Woolhiser, 1973). There was increasing realization that only a recourse to fluid mechanics and process physics would help address such questions, bring about needed improvements to the methods and make them applicable more generally.

Hydrologists thus began to open up the black-box to explicitly capture space, and to characterize water movement in catchments through application of physical (fluid mechanics) principles. The physically based models that were starting to be developed at the time were based on Newtonian me- 
chanics valid at the laboratory or hydrodynamic scale (e.g., Richards equation, St.-Venant equations; Chow et al., 1988), and not at the scale of a catchment. For example, Darcy's law embedded in the Richards equation is based on a local equilibrium assumption to warrant a well-defined potential, implying that internal mixing in the pore spaces is faster than external disturbance, but this is only possible at small scales (Or et al., 2015). This also brought with it the enormous challenge of specifying the (highly heterogeneous) parameter values to go with the equations to represent the landscape heterogeneity (e.g., subsurface soil formations, surface features such as micro-topography, macropores, rills and the stream channel network, and vegetation cover), and the complexity of the resulting flow processes (Freeze, 1974). These problems are at the heart of the scale issue, which remains a major challenge in hydrology in spite of considerable progress made to date, of which I will speak more later.

A key development in this line of reasoning was Peter Eagleson's 1970 book titled Dynamic Hydrology (Eagleson, 1970), which provided a bold theoretical framework for a new hydrology based on the consistent and rigorous application of fluid mechanics principles, i.e., Newtonian mechanics, along with an appreciation of an organized structure behind soil, land surface, and vegetation heterogeneity. Eagleson's treatment of hydrology was a major departure, a paradigm shift, away from the lumped, black-box treatment practiced until then.

Another major milestone was the computer implementation of the coupled governing equations by Allan Freeze (Freeze and Harlan, 1969) that framed the catchment hydrologic modeling problem as a boundary value problem. Progress in this area was advanced by the increasing availability of digital terrain information on topography, soils, vegetation, etc., and computational tools that allowed them to be processed and visualized (Band and Wood, 1988). These data allowed the natural heterogeneity of landscapes to be captured in a more realistic way. Also, it was exciting that new runoff generation mechanisms such as saturation excess overland flow and shallow subsurface stormflow were being discovered in the field (Hewlett and Hibbert, 1967; Dunne and Black, 1970) and could now be faithfully replicated in models using the newly available spatial information, e.g., digital elevation models (DEMs) (Beven and Kirkby, 1979; Beven, 1981; Freeze, 1980; Band and Wood, 1988).

\subsection{Heterogeneity: to resolve or to parameterize?}

The Freeze and Harlan modeling paradigm has remained in force to this day, and several formal models have been developed based on the paradigm, such as the SHE model and variants of the same (Abbott et al., 1986). Due to data limitations and limits on computing power, early modeling efforts were restricted to small catchments, and their goal was limited to generating process understanding, and not so much to making predictions in real catchments (Stephenson and Freeze, 1974; Freeze, 1974). Their adoption and use in real-world applications did not take off for a long time because of their enormous data needs and insufficient computing power and also concerns about the appropriateness of the process physics that could be included in the models at the model element scale (Beven, 1989; Beven and Germann, 1982; Grayson et al., 1992).

As computing power increased many-fold and the landscapes began to be mapped at increased resolution for soil, vegetation and topographic characteristics in many parts of the world, there has been a revival of sorts in recent times, with several models being developed and beginning to be applied to larger (e.g., meso-scale) catchments using more realistic data. Some (of the many) examples include ParFlow (Kollet and Maxwell, 2008), FIHM (Kumar et al., 2009), PAWS (Shen and Phanikumar, 2010), and HydroGeoSphere (Brunner and Simmons, 2012). These modeling efforts are expanding and I will not be surprised if, before long, such models are used not just to reproduce field observations, but also, as in the case of Freeze (1980), to discover and explain previously unobserved phenomena at all scales.

In recent times, as part of climate change studies, modeling has been extended to continental and global scales to serve as the land-surface hydrology components of regional or global climate models. Because of the large scales, spatial resolution of such models in the past tended to be very coarse, on the order of hundreds of kilometers (e.g., bucket model, Manabe, 1969). However, progress is continually being made to improve the resolution from hundreds of kilometers to hundreds of meters, helped along by increased computational power and the availability of terrain information at finer resolutions (e.g., Community Land Model, Oleson et al., 2013). There is now a new thrust to improve the resolution of these models to $30 \mathrm{~m}$ for the whole globe (note: $30 \mathrm{~m}$ is the resolution of terrain information globally available), under the theme of "hyper-resolution modeling" (Wood et al., 2011; Bierkens, 2015; Wing et al., 2017). Concerns and debates about the appropriateness of the physics used in these models, the appropriateness of constitutive relations being adopted (Loritz et al., 2017), and the resulting uncertainty in hydrologic predictions, have not gone away, however (Clement, 2011; Beven and Cloke, 2011; Wood et al., 2012).

An ostensible reason for going for finer resolution, is of course, since now we can do it, i.e., with data availability and computing power, why not, and also since the benefits of hyper-resolution modeling for both science and practice are increasingly becoming evident. For example, hyperresolution models over regional or continental scale domains can track large-scale storm movements and the resulting impacts at scales relevant to human wellbeing, as well as generate insights about large-scale teleconnections between or within regions (Senatore et al., 2015; Fang and Shen, 2017). A more immediate reason, however, is that as one improves the resolution, the (fervent) hope is that all heterogeneity will 
disappear and the governing equations used will match the spatial scales of the processes one is trying to model (e.g., Clark et al., 2015, 2017; Peters-Lidard et al., 2017). In reality, of course, field evidence has strongly indicated that the heterogeneity does not disappear even if one goes to finer scales, and there is a limit to how far we can split the landscape to achieve any desired level of homogeneity and still maintain a continuum (Beven, 1989; Blöschl and Sivapalan, 1995). Besides, the presence of macro-pores and other preferred pathways (Beven and Germann, 1982), and explicit treatment of runoff phenomena relating to the "old water, new water" concept (McDonnell, 1990), present major challenges to traditional continuum representations of water movement on, and particularly below, the land surface based on Newtonian mechanics alone (Beven, 2006). One therefore reaches the alternative conclusion that, whatever grid scale one chooses, there is no alternative but to parameterize the effects of any remaining heterogeneity at the sub-grid scale.

The end result for spatially distributed, physically based models of catchment hydrology is that model development has been caught between two temptations (Hrachowitz and Clark, 2017):

1. split the landscape more and more down to the continuum (hydrodynamic) scale so that heterogeneity disappears as an issue (i.e., heterogeneity is completely resolved);

2. aggregate to some scale at which the effects of heterogeneity are taken care of through simplified treatments with process parameterizations that can account for the effects of all sub-grid heterogeneity.

Advancing technological capability and increased process knowledge at small scales are the drivers towards the former option (Wood et al., 2011). Appreciation of scale effects, including expectation of simplicity through averaging (Sivapalan, 2003), and concerns about predictive uncertainty (Beven and Cloke, 2011) and about a dominant focus on techniques and other quick fixes (e.g., model-data assimilation) over the important search for hydrological understanding (Klemeš, 1986), are the key drivers towards the latter option. The problem of heterogeneity is not unique to hydrology, and applies to all environmental sciences, and approaches to mediate the alternative perspectives presented above may draw inspiration from a quote from ecologist $\mathrm{Si}$ mon Levin (1992):

To scale from the leaf to the ecosystem to the landscape and beyond... we must understand how information is transferred from fine scales, and vice versa. We must learn how to aggregate and simplify, retaining essential information without getting bogged down in unnecessary detail. The essence of modeling is, in fact, to facilitate the acquisition of this understanding, by abstracting and incorporating just enough detail to produce observed patterns... the objective of a model should be to ask how much detail can be ignored without producing results that contradict specific sets of observations, on particular scales of interest.

Levin's (1992) is an argument for "coarse graining”, i.e., formulating models with only the necessary degree of complexity, and against attempts to fully resolve the enormous heterogeneity and complexity of hydrologic processes at progressively smaller timescales and space scales, a perspective which is echoed by hydrologist Thomas Dunne as well (Dunne, 1998).

\subsection{Organized heterogeneity and preferred space scales: REA}

Inspired by the organization that nature exhibits around a hierarchy of spatial scales, i.e., hillslope, catchment, region, etc. (Blöschl and Sivapalan, 1995), there have been concerted efforts to identify whether a characteristic space scale, which reflects the spatial organization and can thus serve as the building block of distributed models, exists in catchment hydrology. This idea is similar to the continuum or REV concept long used in groundwater hydrology with a considerable degree of success (Bear, 1972; Hassanizadeh and Gray, 1979). The argument has been that aggregating the governing equations or process descriptions to this building block scale might lead to simplified (effective) lumped or continuum treatments, obviating the need to split the catchment into smaller elements to capture the effects of heterogeneity. This way of thinking reflects the long-standing conviction, supported by observations, that in spite of the enormous complexity of hydrologic processes in landscapes, catchmentscale hydrologic responses can often be described by simpler models with only a few parameters (Jakeman and Hornberger, 1993; Sivapalan, 2003). Dooge (1986) has argued that catchments are complex systems with some level of organization, and indeed "simplicity out of complexity" is a useful property of such complex systems (Davies, 1992). However, when one opts for the parameterization approach inspired by this reasoning, one still needs to know key features of the underlying heterogeneity, e.g., their statistical distributions or organizational structure (and not necessarily the actual observed patterns). Furthermore, we also need to have information about cross-scale process interactions that might lead to the simplicity we desire (Dunne and Black, 1970; Hassanizadeh and Gray, 1979), and must utilize efficient approaches to incorporate them into models through appropriate model structures and parameterizations (Beven and Kirkby, 1979; Zehe et al., 2014).

Motivated by this reasoning, Wood et al. (1988) pursued this scale question in the context of runoff generation responses at the catchment scale. On the basis of spatial averaging of numerical simulation outcomes from a distributed 


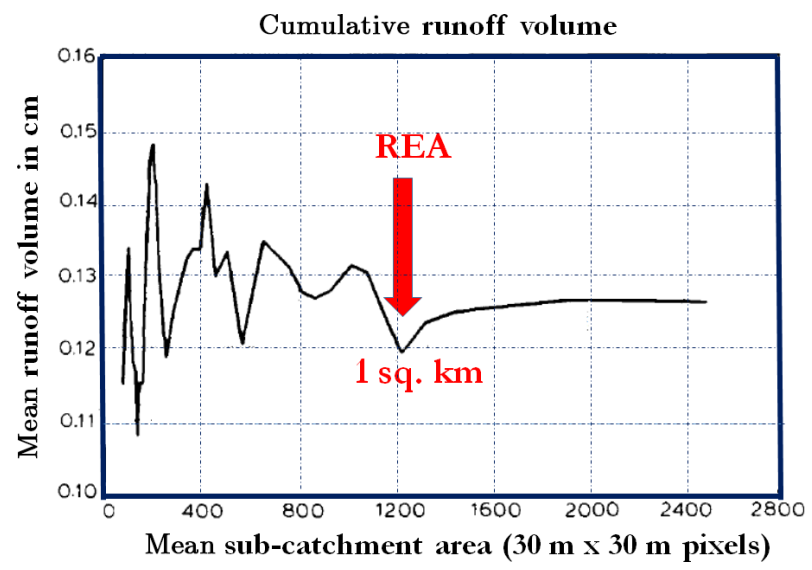

Figure 1. Mean event runoff volume as a function of mean subcatchment area (for the case of variable topography but uniform soils and precipitation). Adapted from Wood et al. (1988).

rainfall-runoff model of hypothetical catchments, Wood et al. (1988) postulated that such a spatial scale could exist, which they called the representative elementary area (REA), and estimated its size to be about $1 \mathrm{~km}^{2}$ (Fig. 1). Subsequent field observations and simulations in New Zealand and Germany supported the idea with some reservations and further refinements (Woods et al., 1995; Didszun and Uhlenbrook, 2008). The claims about both the existence and size of the REA have been questioned by others, based on perceived limitations of the averaging approach used to resolve these questions (Fan and Bras, 1995; Blöschl et al., 1995). A further limitation of the REA of Wood et al. (1988) is that it focused on surface runoff volume, and not its timing. Robinson et al. (1995) explored the change in dominant controls on runoff timing (e.g., hydrograph dispersion) with increased catchment area, and showed that the scale at which the dispersion is maximally reproduced can be affected by whether (fast) surface or (slower) subsurface runoff pathways dominate. The significance of the existence of the REA, whatever its size, is that it is small enough to still account for relevant spatial hydrological variations, and yet large enough to avoid the overwhelming data and parameter needs of small-scale (distributed) models. As a result, despite the reservations, the notion of using a representative watershed scale as the building block towards the development of distributed models (now at a sub-catchment scale) has remained as a working hypothesis for organizing our thought processes in respect of modeling.

Inspired by the possibility that adoption of such a representative scale might lead to simplified yet physically based hydrologic prediction models, Reggiani (1999) developed a new theory of hydrology around this building block, now named the representative elementary watershed or REW, to account for some of the limitations of the earlier REA concept. Reggiani's theory was expressed in the form of balance equations for mass, momentum, energy and entropy writ- ten down directly at the scale of the REW (Reggiani et al., 1998), and an accompanying constitutive theory (Reggiani et al., 1999) to ensure the theory gives rise to a determinate set of governing equations. Subsequently, Zehe et al. (2006) derived soil moisture characteristic (i.e., constitutive) relationships at the REW scale through the upscaling of corresponding point-scale observations. Likewise, Lee et al. (2007) developed a set of closure relations for the many boundary fluxes for the catchment system - between different REWs and between different sub-regions within each REW - again, to account for the effects of sub-grid heterogeneity and process complexity, thus helping to complete the specification of the governing equations representing the catchment response.

The net advantage of the REW approach is that it ends up with the solution of a system of coupled ordinary differential equations (as opposed to a system of partial differential equations, which one obtains if they were to split a catchment into rectangular or triangular elements). Both Tian et al. (2006) and Lee et al. (2007) developed numerical schemes to solve these governing equations, thus forming a new generation of models based on the REW approach that parallel distributed models based on rectangular or triangular finite elements following the Freeze and Harlan paradigm. In this way Tian et al. (2006) and Lee et al. (2007) have contributed to a new class of models of intermediate complexity, resolving processes occurring at scales larger than the size of the REW, and parameterizing those happening at smaller scales (Beven, 2012). Their potential as a new modeling framework has also been highlighted through several applications. For example, models based on the REW approach have been applied to real catchments, generating space-time predictions of the rainfall-runoff response for catchments in Australia (near Darwin, Lee et al., 2007) and in Oklahoma in the United States (Li et al., 2012; Tian et al., 2012). In recent years, these models have been extended to make distributed predictions of sediment and nutrient transport and export at the catchment scale and across the corresponding stream networks (Patil et al., 2012; Ye et al., 2012). It should be noted that in spite of this success, the REW approach has still not taken off, nor has it been widely adopted as would be expected, due to the lack of progress in the development of constitutive and closure relations to account for the effects of sub-REW heterogeneity and process complexity in catchments everywhere; this is discussed next.

\section{Catchments as ecosystems: limits of Newtonian mechanics}

In spite of its promise, and in spite of the progress made so far, the REW approach shares the as yet unsolved problem confronted by all distributed models, which is how to derive or estimate parameters a priori at the scale of the chosen grid (in this case, the REW) without first fully resolving sub- 


\section{Simple system}

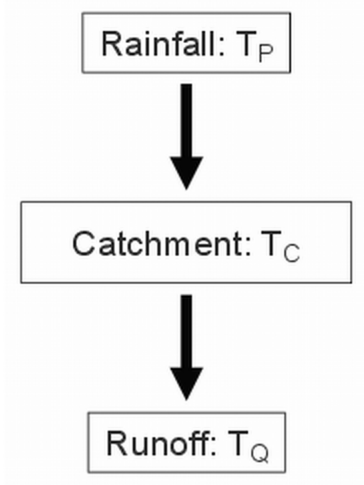

Complex system

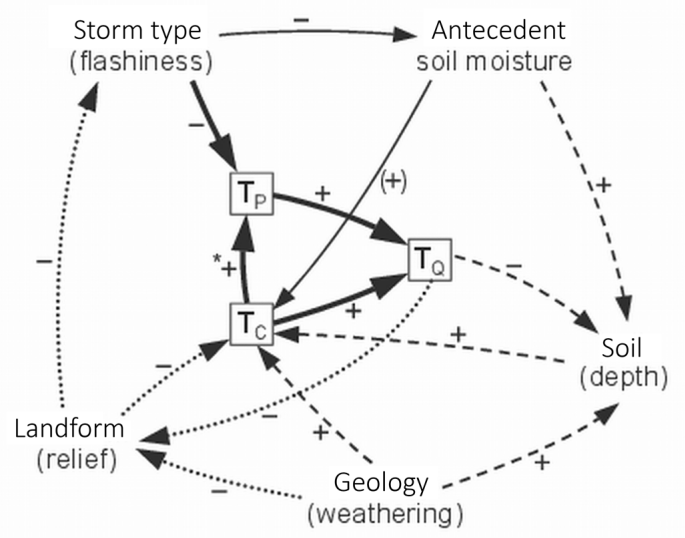

Coupling at different timescales:
- Event timescale ( $h$ )
- Seasonal scale (months)
-- - Soil formation timescale (decades)
….. Landscape evolution timescale (millennia)
$\quad$ * Coupling by filtering
$T_{p}$ duration of flood producing storms

$\mathrm{T}_{\mathrm{C}}$ catchment response time

$T_{Q}$ flood timescale

Figure 2. Simple and complex system representations of timescales contributing to floods. Interactions of multiple timescales make the response an emergent outcome of a complex system. Taken from Gaál et al. (2012).

grid heterogeneity and process complexity, which was the key problem in the first place. The spatial heterogeneity and the resulting cross-scale process interactions can introduce enormous complexity and richness to catchment hydrological responses. However, processes can become even more complex when we extend the analysis to include multiple timescales. When we attempt to make predictions over longer timescales, i.e., longer than events (e.g., months or years), the media within which hydrologic processes operate (i.e., soils, topography, vegetation) may themselves change dynamically or transform permanently (e.g., time-variant macroporosity due to the life cycle of earthworms, Zehe and Sivapalan, 2009; soil swelling and cracking, Savenije and Hrachowitz, 2017). In other words these are not inert objects fixed for all time, as is commonly assumed in deterministic models. Furthermore, if the hydrologic prediction problem is deemed a boundary value problem, as it often is, it also means that the location of the boundary and its condition itself are not fixed, but evolve dynamically as part of the water dynamics, the very dynamics we are trying to predict (see Fig. 2). The end result is that the hydrologic response can no longer be described by Newtonian mechanics alone, and is now the emergent outcome of two dynamic, coupled processes: water flow itself and the changes to the media, both occurring over multiple timescales (Gaál et al., 2012). Note that all of the complex spatial processes we talked about operate in the time domain as well.
The most obvious example of a catchment subsystem that evolves dynamically is vegetation, which is directly involved in the crucial process of evapotranspiration. Vegetation adapts itself dynamically over multiple timescales in response to changing climate and hydrology, even as it has an impact on the hydrology. Also, over much longer timescales it can modify the environment around it (e.g., soil structure, macro-pores, and topography, to name a few). In this way the temporal dynamics of vegetation can also indirectly impact runoff generation processes. As well as evolving with the dynamic hydrology, such biologic activity renders the system even more internally dynamic. The adaptations of vegetation and their modifications of landscapes may be governed by biological or ecological processes, and cannot be captured by universal descriptions based on Newtonian mechanics that focus on flow processes alone; presently their effects on flow can only be described by empirical, place-based relationships. As in the case of spatial upscaling problems discussed before, it is always tempting to ask the question whether the temporal organization of a catchment's hydrologic response, arising from vegetation adaptations to the multi-scale temporal variability of climate and hydrology, and the resulting landscape modifications, could also be averaged to produce a simplified description of catchment response. This question is explored next by highlighting different examples of vegetation (and even landscape) adaptations to natural climate variability and hydrology. 


\subsection{Adaptation strategies by vegetation}

Understanding vegetation adaptation processes is a rich and multifaceted problem, but here I will use examples from my own modeling experience to only illustrate the point about simplicity in spite of complexity, and how this might arise as a result of vegetation adaptations in the time domain. Many existing catchment models, including the ones mentioned before, approximate evapotranspiration rates by vegetation (e.g., forests, grasses) as if they function like humanengineered agricultural crops; i.e., they transpire at a potential rate (e.g., potential evaporation) when the soil is wet, and reduce their evapotranspiration rate when soil moisture falls below the saturation value. In reality, this is not normally the case under native vegetation, and such approximations can lead to serious discrepancies when evapotranspiration is a large fraction of annual water balance, as is the case in most dry places around the world (Sivapalan et al., 1996; Thompson et al., 2011a). This was highlighted in the Darling Range region of south-western Western Australia during field experiments carried out by Silberstein et al. (2001).

South-western Western Australia experiences a strong Mediterranean climate, with warm dry summers and cold wet winters. Field measurements made by Silberstein et al. (2001) in a forested catchment in this region showed that daily evapotranspiration rate (bare soil evaporation plus transpiration) was roughly $2.5 \mathrm{~mm} \mathrm{day}^{-1}$ during a 2-week period in the wet winter phase of the experiment. Remarkably, when the experiment was repeated 6 months later during a 2 -week period following a very dry summer, the evapotranspiration rate turned out to be very much the same, about $2.5 \mathrm{~mm} \mathrm{day}^{-1}$ every day. The assumption that trees, like agricultural crops, might reduce their transpiration rates during dry periods (due to their experiencing water stress) was found not to be the case. It turned out that native Eucalyptus trees in this part of Western Australia have adapted to the strong seasonality of climate (hot dry summers and cold wet winters) by growing dynamic deep roots that tap into a groundwater aquifer present that is over $30 \mathrm{~m}$ deep. Indeed, it was found that tree roots remained always in contact with the deep water table even when the latter fluctuated between summer and winter and between years. The net result is an apparently constant transpiration response by the vegetation, i.e., $2.5 \mathrm{~mm}$ day $^{-1}$ every day.

In a subsequent study at a site near Darwin, in Northern Territory, Australia, Schymanski (2007) reported an altogether different response by native vegetation. This area experiences a monsoon climate, with a wet 4-month period of heavy monsoon rains, followed by 8 months of dry (non-rainy) conditions. Being tropical, potential evaporation is uniformly high during both periods. Water table is present at a depth of about $10 \mathrm{~m}$ all year. Schymanski reported that measured total evapotranspiration rate appeared to follow the variation of surface soil wetness, regardless of the energy available, i.e., potential evaporation (Schyman- ski, 2007). However, the adaptation strategy by the prevailing vegetation was different. In Darwin, the more permanent, deep-rooted trees tap into the groundwater table, just as in Western Australia, and were found to transpire at a rate of $1 \mathrm{~mm} \mathrm{day}^{-1}$ all year, regardless of surface soil moisture. However, in addition, during the wet season, a dense under-story of grasses develops which, like crops, transpires at rates proportional to the surface soil moisture: a peak of 2.5-3.0 mm day ${ }^{-1}$ during the wet season, decreasing as the soil dries during the subsequent dry season, and dropping to negligible values as the grasses completely senesce and dry out. Once again, a slightly more complex, almost predictable transpiration pattern that arises via complex adaptation strategies adopted by the vegetation to the climate and hydrology.

Two different places, two different adaptation strategies by vegetation that has developed in each setting, yet permitting a simplified transpiration pattern in each case: in both cases, the strategies used by the vegetation are different from what is normally assumed for agricultural crops. This raises two issues: if one wants to develop a predictive model of evapotranspiration for a specific place, then the adaptation strategy adopted by the vegetation that develops locally must be known a priori. Newtonian theory by itself cannot predict the vegetation and its adaptation strategy one is likely to encounter in a given place, both of which may be governed by (the as yet unknown) biological/ecological laws at the scales of interest to us. The adaptation strategy adopted by the vegetation would be relatively easy to determine, given the kind of observational evidence available to Silberstein et al. (2001) or Schymanski (2007). Few places would have that kind of field evidence, however. In a catchment context, many more places will have rainfall-runoff data only, from which the adaptation strategy adopted by vegetation may have to be inferred (with a lot more ambiguity, given the kind of limited data, especially in the absence of evapotranspiration data). The fact that prevailing vegetation in different places may use different adaptation strategies, in the absence of such supporting data, also opens the way for much freedom or pluralism in the development of predictive models, as opposed to a universal model that would be expected from Newtonian mechanics.

\subsection{Ecosystem function and data-based inference}

A key observation from the last section is that the dynamics of evapotranspiration is intimately connected to that of vegetation adaptation. We can broaden this argument to include other catchment responses as well, such as runoff. We are quite used to treating runoff generation as a physical process, governed by Newtonian mechanics (Larsen et al., 1994). This presumes that we know a priori what mechanism of runoff generation dominates in a given place. However, Newtonian mechanics alone may not be able to determine a priori (i.e., without field evidence) the dominant runoff gen- 
eration mechanism in any given place. Based on field evidence Dunne (1978) provided a perspective on climate, soil, topography and vegetation controls on dominant runoff generation mechanisms, popularly known as the Dunne diagram. To this day, the Dunne diagram has continued to defy explanations based on Newtonian mechanics alone (Larsen et al., 1994; Li et al., 2014). Vegetation adaptation may again be the chief cause of this phenomenon, e.g., vegetation perhaps adapting itself and adapting the environment around it (i.e., soils, topography) in such a way that it can retain soil moisture longer in arid environments and drain water sooner in wet environments. Also, forest soils are known to have higher surface infiltration capacities, which also impact their stormflow response. Thus, "forest" vegetation type becomes a property linked to infiltration and runoff generation, as well as to evapotranspiration.

Given this field evidence on evapotranspiration and runoff generation, and given the limitations of the more reductionist approach based on Newtonian mechanics, one is tempted to look for a complementary but holistic approach that can accommodate the adaptation of catchment properties (i.e., vegetation, soils) to environmental conditions. What if, instead of treating catchments as physical or mechanical systems, we consider them more broadly as ecosystems. Then the same processes, i.e., evapotranspiration and runoff generation, could be deemed a catchment's ecological responses, as part of its overall ecosystem "function". This was the wisdom behind the "functional" approach proposed by Black (1997), who framed a catchment's hydrological responses to precipitation more broadly as partition, storage, transmission, and release (see also Wagener et al., 2007), as opposed to pointscale processes (e.g., infiltration), in this way aligning them to the catchment's ecosystem function.

Another observation from the last section is that in spite of the known complexity of hydrologic processes at small timescales (rain events) and space (point) scales, which Newtonian mechanics may well be able to capture under some circumstances, catchment organization and ecosystem adaptation impart a level of simplification to hydrological responses at the catchment scale. One example is the dynamics of evapotranspiration seen in forested catchments in Perth and Darwin. Another example is the well-known fact that the discharge of the groundwater aquifer to streams can often be represented by simple linear reservoir theory, characterized by a mean residence time, in spite of the known complexity of flow processes operating at small scales, governed by Darcy's law (Savenije, 2017). This intriguing connection between micro-scale complexity and macro-scale simplicity has been an unsolved problem in catchment hydrology (Dooge, 1986; Sivapalan, 2003). The challenge for predictions is that the mechanisms through which such transformations from complexity to simplicity happen are largely unknown. If the biological or ecological laws or principles that govern them at the catchment scale were known, we might then use them to derive simpler, holistic parameterizations of hydrologic responses. Until such laws become available and lead to the development of universal predictive models, however, the problem lends itself to a plurality of modeling ideas, including data-driven approaches that rely on inferences from available rainfall-runoff data.

Wittenberg and Sivapalan (1999) presented an interesting and insightful implementation of the data-driven inference idea. They performed diagnostic analysis of rainfall-runoff data in several catchments in Western Australia (WA). This first involved analysis of streamflow recessions (i.e., following the end of individual rainfall events) during different times of the year, and in WA's seasonal climate, attributing differences in the slopes of the recession curves to changing evapotranspiration (ET) within the year. This made it possible to back-calculate the unknown ET from the recession curve slopes, and thus piece together a simple groundwater balance model for the catchments. This approach to databased inference was later extended by Kirchner (2009) to UK catchments, calling the approach "doing hydrology backwards". In both cases, however, the power of the approach was due to the apparent simplicity of the hydrologic response manifesting itself at the catchment scale, which results from the spatial landscape organization and the temporal adaptation of the catchment ecosystem to the prevailing climatic variability.

Following the lead of Wittenberg and Sivapalan, Jothityangkoon et al. (2001) and Atkinson et al. (2002) extended the data-based inference idea further by treating the catchment's observed rainfall-runoff response as a reflection of its ecosystem functions (i.e., partition, storage, transmission, and release) but manifesting differently at different timescales. They assumed that the ecosystem functions are reflected collectively in several runoff signatures (i.e., temporal patterns extracted from streamflow data at different timescales), through which it was assumed that the catchment reveals its internal dynamics or functioning (see Fig. 3). These streamflow signatures, e.g., the regime curve (monthly timescale), flow duration curve (daily), or flood frequency curve (multiple timescales), are thus seen as outward manifestations of internal ecosystem functioning, and can therefore be deemed emergent (temporal) patterns.

The functional insight and the realization that catchment responses can show organization along timescales gave rise to a new approach to the modeling of catchment rainfallrunoff responses, called the top-down or downward approach (Klemeš, 1983; Sivapalan et al., 2003). We might as well call it the functional approach, following the lead of Black (1997). This modeling approach is diametrically opposed but complementary to the bottom-up or upward approach to model development based on Newtonian mechanics (Klemeš, 1983), an example of which is the REW approach of Reggiani et al. $(1998,1999)$ discussed earlier. The idea behind the downward or functional approach is to develop models step by step, but starting at long timescales (e.g., the annual timescale, as in the case of Jothityangkoon 


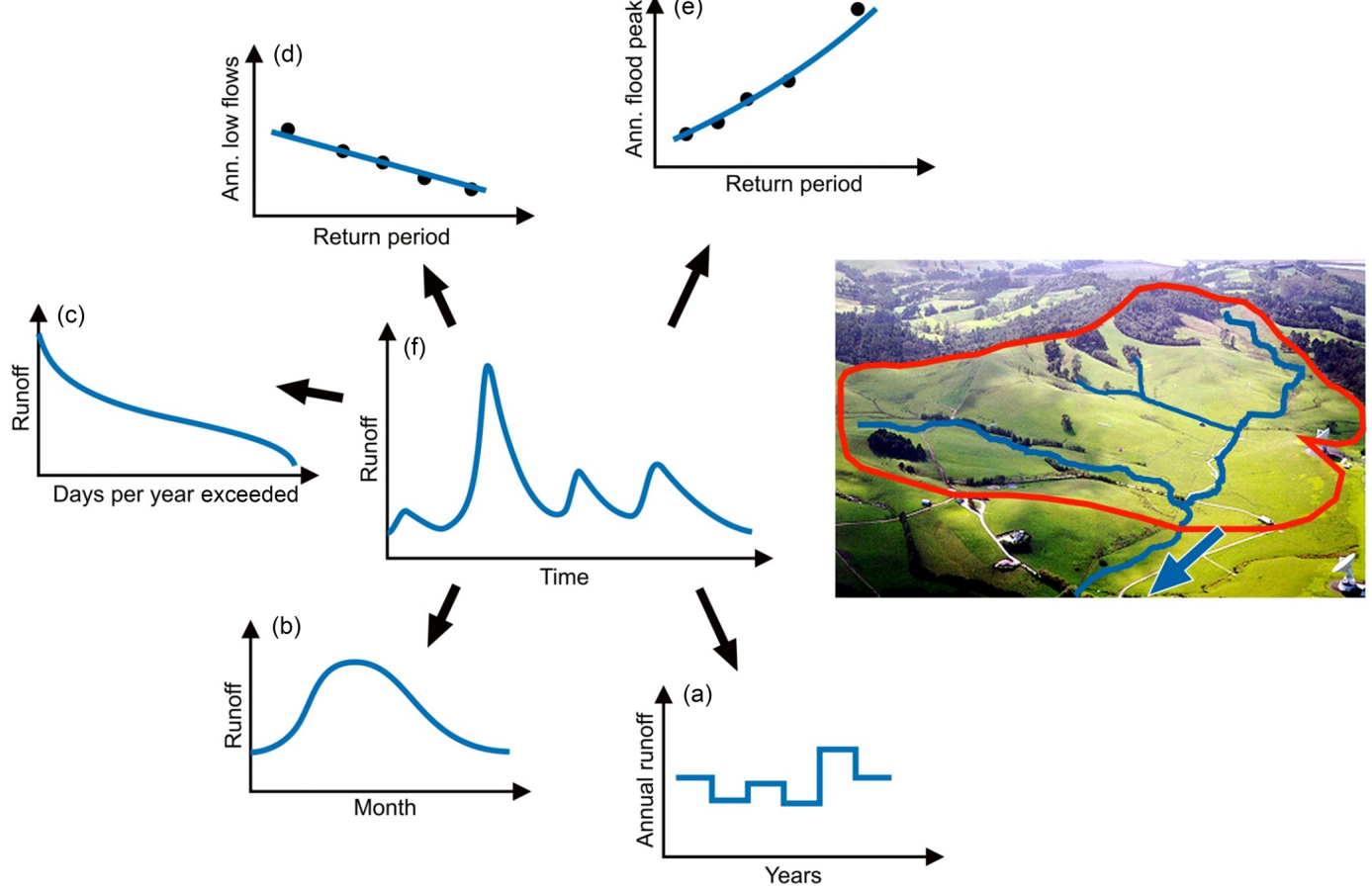

Figure 3. Runoff signatures deemed emergent patterns reflecting the functioning of the catchment ecosystem. (a-f): annual runoff, seasonal runoff, flow duration curves, low flows, floods, and runoff hydrographs. Taken from Blöschl et al. (2013).

et al., 2001). Once a simple (simplest possible) model is developed that reproduces the runoff signature at the annual scale, i.e., inter-annual variability, one then moves down to the monthly timescale, and adds just enough functional complexity to the model to match a new signature, now at the monthly timescale, i.e., the regime curve. If partitioning is the main function that is accommodated at the annual timescale, storage and release could be functions added at the monthly scale, and so on. This process continues until a model is developed that is able to reproduce signatures extracted from streamflow data simultaneously at all timescales (Jothityangkoon et al., 2001; Atkinson et al., 2002). The topdown modeling approach bears some similarity to the databased mechanistic modeling approach proposed earlier by Peter Young of Lancaster University, and illustrated in Young and Beven (1994) and Young (2003), as discussed in Sivapalan and Young (2005).

Interestingly, the "functional" models, developed in a topdown way through inference from data (e.g., Jothityangkoon et al., 2001; Atkinson et al., 2002), are in many ways similar to what have long been known as conceptual models, which have been developed from the 1960s, beginning with the Stanford Watershed Model (Crawford and Linsley, 1966). These conceptual model types can be lumped (at the catchment scale) or distributed (at the sub-catchment scale), and are also developed without recourse to Newtonian mechanics. Examples (among numerous other models) include the Tank Model (Sugawara, 1967), HBV (Bergström, 1976),
LASCAM (Sivapalan et al., 1996), and the FLEX generation of models proposed in recent times (Fenicia et al., 2011; Gharari et al., 2011). Both conceptual and top-down model types take the form of a combination of inter-connected storage reservoirs that mimic the functioning of different parts of a catchment, both attempt to provide some kind of mapping between landscape structure and model structure (Sivapalan, 2005), and both types contain strong subjective elements. The main difference is the thought process that goes into developing these models. Development of top-down models follows a systematic procedure to decipher the model structure from observed rainfall-runoff variability at multiple timescales. In the case of traditional conceptual models, the model structure is chosen, ostensibly but often arbitrarily, to reflect the functioning of parts of the catchment, with the opportunity to further refine it through calibration or confrontation with rainfall-runoff observations. In another sense, both model types are also similar to physically based models of intermediate complexity arising from the REW approach (e.g., Tian et al., 2006; Lee et al., 2007), in that all three model structures are expressed in the form of coupled ordinary differential equations that reflect water balances of individual compartments (or storages). 


\section{Newtonian mechanics vs. ecosystem function: impasse and reconciliation}

In the preceding sections I outlined two complementary approaches that hydrologists have pursued over the past 5 decades to make catchment-scale predictions. Using the terminology of Klemeš (1983), subsequently expanded by Sivapalan et al. (2003), these can be termed the upward (or bottom-up reductionist) and downward (top-down ecosystem or functional) approaches. The upward approach fundamentally involves application of Newtonian mechanics, either through spatially distributed models that attempt to explicitly resolve spatial heterogeneity, or through semidistributed (e.g., REW) models that attempt to parameterize the effects of sub-grid heterogeneity, while keeping the essential physics. The downward approach to model development, on the other hand, involves making inferences from catchment-scale rainfall-runoff data (and other responses, e.g., evapotranspiration, if available).

The advantage of Newtonian mechanics based models is that the role of spatial gradients in controlling hydrologic processes, at least in principle, can be explicitly captured, and so the fidelity of process descriptions at small scales can be guaranteed (at least in principle). However, they have the disadvantage that they cannot (yet) account for the functioning of the catchment as an ecosystem, which is defined by process interactions in the time domain, the biological/ecological laws behind which are yet to be discovered in the catchment hydrologic context and incorporated into the models. The top-down approach to modeling has the advantage, being derived from rainfall-runoff data, that it can capture the holistic nature of catchment functioning. On the other hand, it cannot (yet) unambiguously account for the physical laws that govern flow processes in landscapes, especially in the spatial domain.

Indeed, it has been said that "bottom-up reductionisttype models are best suited to represent "known" knowledge, and are at their weakest to reveal "unknown" knowledge (R. Silberstein, personal communication, 2017); vice versa for top-down ecosystem-type models. In this sense, the biggest strength of the top-down approach is also the biggest drawback of the bottom-up approach, and vice versa (Sivapalan et al., 2003). These two perspectives will remain irreconcilable until major breakthroughs are made in our understanding of multi-scale spatial heterogeneity and temporal variability, no doubt governed by Newtonian mechanics at small scales, the resulting cross-scale interactions and adaptations at long timescales governed by ecological laws, and the understanding of how these contribute to whole ecosystem function and manifest themselves in more holistic and simplified parameterizations of catchment responses (Sivapalan, 2005; McDonnell et al., 2007). Presently, in this context, we are at an impasse.

One of the clearest manifestations of the impasse in modeling is in the uncertainty in the resulting hydrologic predic-

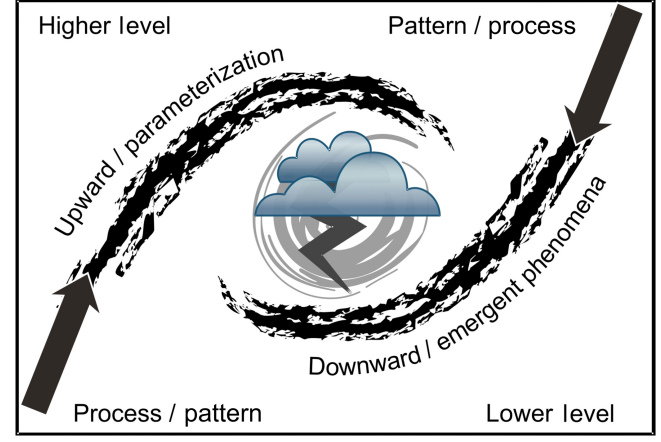

Figure 4. Reconciliation of downward and upward approaches break from a reliance on parameterization of lower-level features to discovery and explanation of emergent phenomena at the higher level. Taken from Sivapalan (2005).

tions (Beven and Binley, 1992). Neither approach is complete in terms of its theoretical foundation to generate the predictions we need. In the case of bottom-up models based on Newtonian mechanics, the predictive uncertainty arises from an inability to characterize the heterogeneity of landscape properties accurately, the lack of complete knowledge or understanding of hydrologic processes in the real world, and the inability to capture them in the models. In the case of top-down or functional models that depend on data-based inference, equally there is uncertainty arising from the diversity of catchment adaptations to climate and consequently in the plurality of model structures. In addition, there is further uncertainty due to the inability to unambiguously estimate the parameters through calibration, in the absence of physical guidance or universal laws to constrain the parameter values. In a broad sense, the uncertainty arises from both inadequate understanding of catchment behavior (epistemic uncertainty) and an inability to characterize catchment heterogeneity fully (aleatory uncertainty) (Beven, 2016). Further progress in modeling will thus depend on our ability to break the impasse between these two different modeling approaches by changing the science questions that have been behind hydrologic research over the past decades (Sivapalan, 2009).

\subsection{Breaking the impasse: change the question}

True reconciliation, however, is unlikely to come about if we stay within the existing paradigms, through mere refinements to existing approaches to estimation and prediction. Reconciliation between Newtonian mechanics and ecosystem function based approaches will require a new era of research aimed at explanation and discovery rather than estimation and prediction (see also Burt and McDonnell, 2015). Reconciliation will require, on the one hand, that we understand the functional role of landscape heterogeneity, and on the other hand, the physics (i.e., mechanics or thermodynamics) underpinning ecosystem function. This might require go- 
ing beyond Newtonian mechanics and searching for other universal laws or organizing principles that explain ecosystem functioning of catchments in particular places. Instead of parameterizing the effects of heterogeneity, the focus should be on recognizing it as an emergent pattern and coming up with explanations to describe how it came about and discover its ecosystem function (Fig. 4, Sivapalan, 2005). The modeling question should no longer be whether we can explicitly account for the effects of heterogeneity mechanistically, but whether its ecosystem function can be reproduced (McDonnell et al., 2007; Schaefli et al., 2011). In other words, to move forward towards both understanding and improved predictions, research goals and associated scientific questions must broaden from just estimation to explanation.

\subsection{Moving from estimation to explanation: focus on phenomena}

As we have seen, the focus on estimation goes back to the beginnings of engineering hydrology. In spite of the enormous progress we have made in our ability to make predictions, these advances have not contributed towards generalized theories that operate universally across catchments and places. General theories are very much needed to bring about the reconciliation of the diversity of modeling approaches we now have and achieve a unification of the field. Hydrologic research will thus have turn to new types of questions (Sivapalan, 2009), which are focused on explanation and discovery, perhaps as a necessary prelude to prediction. Organization of catchment responses and the patterns of ecosystem function that one observes in the real world are no longer objects to be mimicked by our models ("grist to the calibration mill", à la hydrograph fitting), but need to be seen as emergent phenomena. The enormous computational power and data availability that we now have should be utilized to discover and/or explain previously unobserved or unexplained phenomena at all scales and places (Li et al., 2014; Dunne, 1978). This may herald a major culture change in the way we do research.

Phenomena abound in hydrology, differing in complexity and richness, and arising in different contexts, which warrants a separate review article by itself, given their increasing importance in hydrology research. Examples of phenomena in catchment hydrology include the old water-new water concept (McDonnell, 1990), the pan evaporation paradox (Roderick and Farquhar, 2004), the Budyko hypothesis (Budyko, 1974), the proportionality hypothesis that lies behind the success of the SCS-curve number method (Wang et al., 2014), and the linear reservoir approximation to groundwater contributions to streamflow (Savenije, 2017). The goal of research will increasingly revolve around coming up with plausible hypotheses about their causes and testing them out through further observations or targeted modeling. If the explanations hold in several places, then it contributes to accumulation of knowledge and understanding, and eventu- ally to general theories and underlying organizing principles. There is a long history in other branches of hydrology where such a focus on phenomena has led to major advances in hydrologic understanding. One can point as examples the phenomenon of macrodispersion in groundwater transport in heterogeneous porous media (Gelhar and Axness, 1983) and that of hysteresis in vadose zone hydrology (Hassanizadeh et al., 2002), where sound explanations were found while remaining within the Newtonian and/or thermodynamic frameworks.

Until recently, under the weight of the dominant estimation/prediction (i.e., hydrograph fitting) paradigm, inadequate attention has been given to the study of phenomena in catchment hydrology. Here I will illustrate, through two simple examples, how the physical or functional causes of phenomena can be explored, and how this might contribute to generalized understanding. The two examples I present here involve an apparent power-law relationship with catchment size (area). The first one involves annual maximum flood peak (scaled by catchment area), in this case, taken from several nested catchments in the Appalachian region of the United States (Fig. 5a: Smith, 1992; Robinson and Sivapalan, 1997; Sivapalan, 2005). The second one involves a sediment delivery ratio (the fraction of eroded sediment at an event scale that actually reaches the catchment outlet; Fig. 5b: Lu et al., 2005). Even though these examples are obtained from specific places, the phenomena themselves are universally observed. The question is, why is it a power law? Is there a causal explanation? Answers to such questions test our understanding of the underlying processes and the interpretation of observations of all kinds.

Robinson and Sivapalan (1997) showed that the observed power law can be explained by a simple argument, supported by a simple linear "bucket" model with two different timescales (event duration, and a mean response time that is a function of catchment area, due to the geometric relationship between length of travel and area), and an understanding of rainfall variability. If rainfall intensity is a constant during a single storm event, the magnitude of the flood peak can be analytically derived based on storm duration and mean response time: it does not follow the power law (see the dotted line... in Fig. 5a). Firstly, the introduction of within-storm rainfall variability increases the flood peak for small catchments (due to their fast response), but has no impact in large catchments (denoted by the symbol "***" in the figure). Secondly, the introduction of betweenevent interactions and seasonality increases the flood peak for large catchments (due to their effect on antecedent conditions), but has no influence for small catchments (denoted by o o o). Their combination leads to a combination of the two effects (denoted by - - - and -): flood peak is increased for small catchments (because of within-storm variability) and for large catchments (because of interaction between events and/or seasonality). So what looks like a power law is really an emergent pattern that falls out as a result of a complex in- 

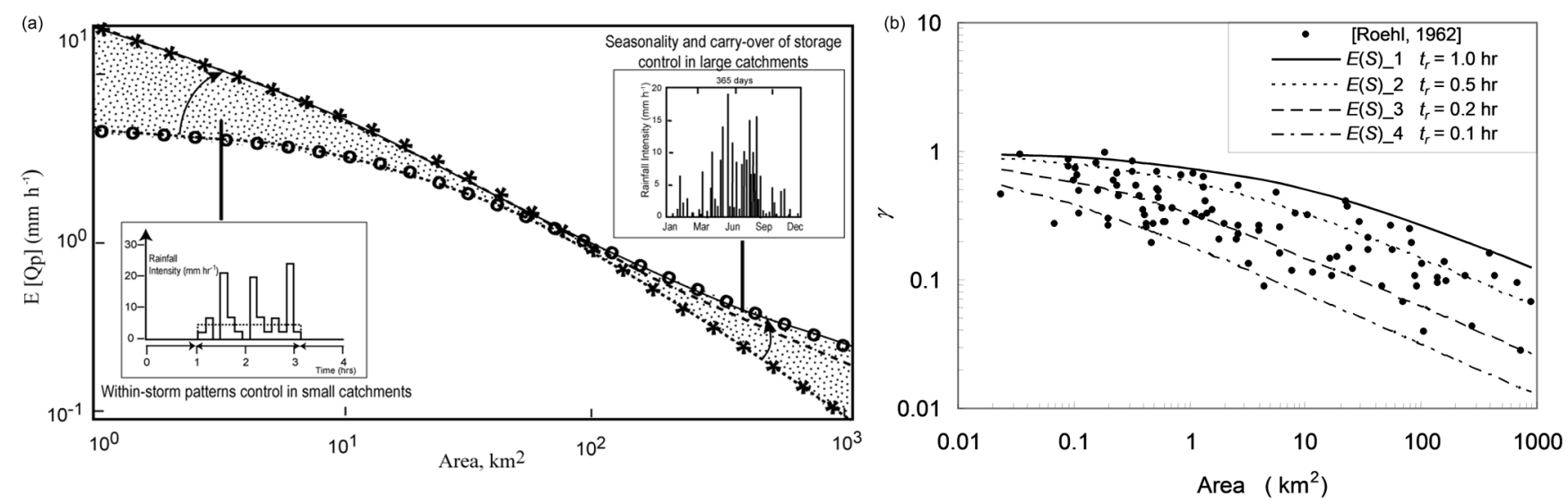

Figure 5. Explaining power-law relationships as emergent phenomena arising from timescale interactions: (a) mean annual flood as a function catchment area, $A$, in the Appalachian region (taken from Sivapalan, 2005); (b) sediment delivery ratio (SDR) $\gamma$ as a function of catchment area for different values of rainfall duration $t_{\mathrm{r}}$ and an assumed power-law relationship of mean channel travel time $t_{\mathrm{c}}$ with $A$ (taken from Lu et al., 2005).

terplay across different timescales, and the geometry of the catchment's organization.

The scaling of the sediment delivery ratio is an even more complex phenomenon to explain (with considerable scatter; see Fig. 5b), because it involves not only runoff processes as discussed above, but also sediment transport processes. Even in this case, however, Lu et al. (2005) proposed an explanation that was similar, indeed one that followed that of Robinson and Sivapalan (1997). Lu et al. too used a simple conceptual model that consisted of two linear stores arranged in series: a hillslope store that addresses transport of sediment to the nearest streams and a channel store that addresses sediment routing in the channel network. They showed analytically that, as with Robinson and Sivapalan (1997), the spatial scaling of the sediment delivery ratio (as an emergent pattern) can be explained, to first order, in terms of the interactions between several timescales (i.e., storm duration, hillslope/channel travel times, and two depositional timescales), and also catchment geometry as before.

I used these simple examples to also highlight the effects of the interactions between multi-scale temporal variability of both climate inputs and catchment response, and how they tend to generate emergent patterns due to the resonance that is generated through these interactions, even in the absence of adaptations of vegetation or catchment properties. In other words, the way that the catchment responds to a sequence of events is different from the way it responds to a single event, indicating that the response of the catchment must be considered holistically across multiple timescales. The importance of timescale interactions has also been highlighted in other contexts to explain several environmental phenomena: power-law-type streamflow recessions resulting from landscape heterogeneity (Harman and Sivapalan, 2009); the effect of rainfall event variability on the pesticide leaching risk of groundwater (McGrath et al., 2010); and climate controls on vadose zone contaminant transport (Harman et al., 2011). This issue will be explored in more detail in later sections using an expanded, co-evolutionary framework.

\subsection{Towards explanation and extrapolation: new kinds of models, new kinds of phenomena}

As the focus turns from estimation to explanation, the types of models one uses may also need to change. It is not an accident that in the two examples discussed above, I have demonstrated how simple models are able to provide firstorder explanations of otherwise complex phenomena. In this age of big data, data mining and hyper-resolution modeling (Wood et al., 2011; Peters-Lidard et al., 2017), one might be surprised that I advocate the use of simple models. I do this deliberately because the focus here is not on prediction of the complete system response in one place with all its gory complexity, but as per the Einstein quote below (see the earlier quote from Simon Levin), on the ability to explain complex, possibly universal phenomena more simply, and thus contribute to accumulation of knowledge and understanding.

If you can't explain it simply, you don't understand it well enough. - Albert Einstein

Note that the simplicity I advocate here is, in the words of James Dooge, a "search for... a rational simplicity, not the simplicity of crude assumptions,... or assuming the difficulty out of the way" (Dooge, 1995). In the spirit of the top-down reasoning, as also argued by Dooge (1995), we will be better off starting with simple models targeted on the phenomenon of interest, not models of everything, and increasing the complexity only as needed. Dooge suggested linearization and similarity analysis as effective ways to simplify models and gain understanding of phenomena, which was also the case in the previously highlighted work of Robinson and Sivapalan (1997) and Lu et al. (2005). 
Phenomena of interest to us can be dynamics (temporal patterns) in a single place and on a range of timescales (Burt and McDonnell, 2015). Similarly, in the space domain, phenomena can be spatial patterns in a single place (within a catchment, Blöschl et al., 2016) or spatial patterns between places (catchments) or scales (as in the two examples above), extending all the way to regional or global patterns (Blöschl et al., 2013). Increasingly, as discussed before, the focus turns towards developing a generalized understanding of whole catchment responses and ecosystem functioning, and the discovery of universal laws. Therefore, it is no longer sufficient to study phenomena relating to a single place or a few places. Increasingly, the phenomena of interest to us will come from simultaneous observations in many different places with different histories of the kinds of timescale interactions shown to be critical in the two examples presented above (Hipsey et al., 2015), and the synthesis of data collected from across places, scales and processes (Blöschl et al., 2013).

\section{Timescale interactions and catchment co-evolution: the Darwinian approach}

Understanding the reasons for differences in required model structure between catchments, including the controls of climate and landscape properties, may be a good starting point in the search for more generalized understanding, by drawing from many different places with different histories. Atkinson et al. (2002) and Farmer et al. (2003) implemented the top-down modeling approach, in a comparative way, to two dozen catchments around Australia and New Zealand. They found systematic variations in model structure, with the differences reflecting differences in climate and in how vegetation and soils may have adapted to the climate. The modeling studies indicated evidence of a hierarchy of required model structures, with changing timescales (i.e., annual, monthly, daily), and with changing aridity. For example, the required model complexity increased with decreasing timescales, and increased with increasing aridity. The argument could thus be made that the required model structure, reflecting the functioning of a catchment, is itself an emergent property in terms of how the catchment has adapted itself to the prevailing climate and geology.

\subsection{Catchments "marching to a different drummer": comparative hydrology}

In order to shed more light on the required level of model complexity, Jothityangkoon and Sivapalan (2009) compared a dozen catchments from all around Australia and New Zealand, using the same top-down modeling approach described above (i.e., matching streamflow signatures on a range of timescales). They carried out a diagnostic analysis in each catchment that focused on elucidating the climate con- trols on one particular signature, i.e., inter-annual variability of runoff. In particular, the authors were interested in discovering the aspect of the within-year rainfall variability (i.e., storminess, seasonality) that may have a dominant control on the observed inter-annual runoff variability. The diagnostic analysis adopted involved running calibrated top-down hydrological models in each catchment, but now with artificial rainfall inputs that included storminess and seasonality separately, before being combined. The outputs from the model in each catchment, for each of the artificial climate inputs, were compared to the observed inter-annual variability. The question pursued was: what combination of within-year climate variability (seasonality, storminess) is needed to reproduce the observed inter-annual variability of runoff?

The study found that in catchments in Queensland in north-eastern Australia, inter-annual variability of runoff was most sensitive to storminess (not seasonality), whereas in catchments in Western Australia and South Australia, seasonality was the feature that contributed most to the observed inter-annual variability. This finding is remarkable, in that the climate of Queensland is indeed dominated by storminess (i.e., a small number of large storms), and the climates of South and Western Australia were indeed dominated by strong seasonality. The outcomes from these diagnostic analyses thus indicated that the water balance dynamics of catchments (i.e., model structure and parameters inferred from the data in a top-down way) somehow "resonate" with the dominant within-year variability, i.e., storminess in Queensland and seasonality in Western Australia. In other words, and paraphrasing American naturalist Henry David Thoreau, these results indicated that each catchment is "marching to a different drummer", the drummer being the variability of climate drivers present in a given place.

If a (wo)man does not keep pace with (her)his companions, perhaps it is because (s)he hears a different drummer. Let (her)him step to the music which (s)he hears, however measured or far away. - adapted from Henry David Thoreau: Walden, 1854.

The modeling results also reaffirm the ecosystem or functional view presented earlier, including the argument that there is much to be gained by making inferences from observed rainfall-runoff time series. The results also raise the hope that a more universal understanding of both ecosystem function and catchment response and their relationship with climate and geology may be gained by repeating these modeling and diagnostic studies simultaneously in many more catchments around the world, in a comparative way, across gradients of climate and geology. This leads to the notion of comparative hydrology, first introduced by Falkenmark and Chapman (1989), and defined more broadly in the next section by linking it to catchment co-evolution. 


\subsection{Catchment co-evolution and Earth system science: a Darwinian view}

Berghuijs et al. (2014) extended the above comparative hydrology approach to the modeling of seasonal water balances of over 400 catchments across the continental United States. On the basis of these modeling results they came up with a classification of observed seasonal water balances (i.e., regime curve, a key signature of runoff variability), expressed in terms of three driving factors: climate aridity, seasonality (i.e., relative timing of the precipitation within a year), and the fraction of snow as precipitation. On the basis of this similarity analysis, they identified 10 dominant catchment classes among the 400-odd catchments. Not surprisingly, they found a geographic aspect to the locations of the 10 classes, in that they were clustered geographically, influenced by the slow climatic and geologic variations across the continent. In addition they found that similarity of seasonal water balances carried over to have an imprint on betweenclass differences in several other signatures of runoff variability, such as the flow duration curve or flood frequency curve, and yet there was also considerable within-class variability due to other climatic and landscape factors.

An even more interesting finding from Berghuijs et al.'s (2014) results, however, was that the regional mapping of catchments on the basis of similarity of seasonal water balances was closely aligned with the regional mapping of not only vegetation classes and ecoregions (i.e., the different ways ecologists map vegetation and ecosystems), but also soil orders. This clearly indicated that the seasonal water balance response is not just about the partitioning of incoming precipitation into spatially resolved hydrologic processes, i.e., runoff, evaporation and storage change. In fact, it is both a contributor to, and an outcome of, the co-evolution of physical, biological and pedologic processes governing vegetation establishment and adaptation, and soil formation, as well as water balance, which all together reflect an underlying ecosystem function. Indeed, it is well known in the ecological literature that it is the seasonal water balance that determines vegetation types that become established in a given place, including their functioning and productivity (Stephenson, 1990; Robinson et al., 2012).

One can speculate therefore that the phenomenon of each catchment "marching to a different drummer" is a reflection of vegetation adapting to (and in turn changing) the environment around it (e.g., hydrology, soils), in response to the fluctuating water and energy supply at any place of interest (Sivapalan and Blöschl, 2015). This is tantamount to the soils, vegetation and topography belonging to a catchment co-evolving together in response to the climate above and geology below through both land-forming and life-sustaining processes operating and interacting across multiple timescales (Fig. 6). The focus can no longer be on just hydrological processes, but all land surface processes that operate together and feed back on each other, which thus takes hydrology into the

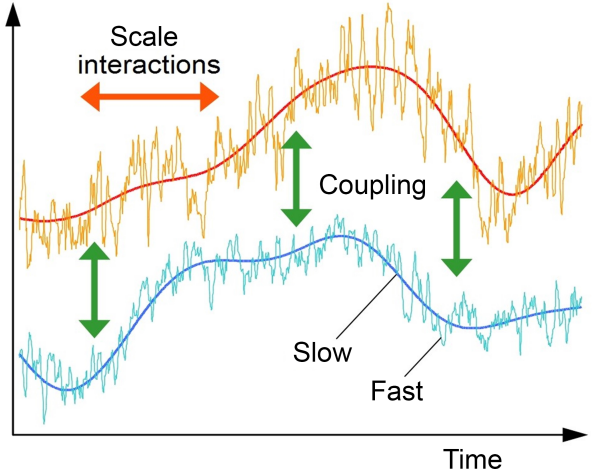

Figure 6. Co-evolution resulting from the interaction of a number of processes (at least two: one represents hydrological processes and the other landscape physical or ecological or social processes), each of which consists of fast and slow components producing emergent dynamics. Redrawn from Sivapalan and Blöschl (2015).

realm of Earth system science. With this broader view, the focus of analysis is therefore no longer on streamflow signatures alone, but also on signatures arising from the coevolution of Earth system processes, such as vegetation and erosional patterns that one sees in landscapes (Sivapalan, 2005; Brantley et al., 2017). Examples include patterns in measured evapotranspiration at individual (e.g., FLUXNET) sites (Thompson et al., 2011a), regional patterns of evapotranspiration measured by remote sensing (Cheng et al., 2011), and vegetation, soil and micro-topography patterns in landscapes on a range of scales (Thompson et al., 2011b; Saco et al., 2013; Harman et al., 2014). These are the kinds of ecohydrologic and hydrogeomorphic phenomena that will need to be further explored in the future and synthesized to generate the new understanding and new theories required to close the gap between bottom-up (reductionist) and topdown (ecosystem) approaches to modeling.

These outcomes of co-evolution, framed as emergent phenomena, may be different in different places, because of differences in the history of co-evolution and initial and boundary conditions of climate and geology. Comparative hydrology, i.e., comparing many catchments in different places along gradients of climate and geology, helps us to shed light on their co-evolution, just as Charles Darwin interpreted differences between animals, birds and plants he found in his travels through the lens of their natural history (Harman and Troch, 2014). The Darwinian approach to comparative hydrology embraces the history of each place, including features that are relics of historical events, as central to understanding both its present and its future (Blöschl et al., 2013). The essence of the Darwinian approach then is to develop generalizations beyond individual catchments through learning from differences between catchments, and interpreting them as legacies of past co-evolution. 


\subsection{Hydrologic similarity and catchment classification: steps towards generalization}

Given the co-evolved nature of catchments, their structure and function, and the resulting hydrologic responses, explanation of the similarity and differences between catchments must take a more Darwinian approach that emphasizes timescale interactions specific to a place, and how the catchment ecosystem may have adapted to these. While there can be considerable diversity and randomness allowed in Darwinian co-evolution of catchments due to contingency effects (Beven, 2015), patterns and connections may yet be discernible which may lead to relationships of more general applicability. One approach to creating order in an otherwise heterogeneous world, widely adopted in chemistry and ecology, is through the process of classification. As in the case of the periodic table in chemistry, classification of catchments based on hydrologic similarity may be used to group catchments, helping to simplify relationships and generalize findings. Hydrologic similarity is the foundation for the transfer of information from one catchment to another, including from gauged to ungauged catchments, and was the basis for the successful outcomes of the Predictions in Ungauged Basins (PUB) initiative (Sivapalan et al., 2003; Blöschl et al., 2013; Hrachowitz et al., 2013). The PUB synthesis study by Blöschl et al. (2013) framed hydrologic similarity in terms of several signatures of runoff variability, such as the flow duration curve and the flood frequency curve. The diversity of catchment responses is such that no two catchments are so similar that all signatures are the same between them, and so for prediction purposes one concentrates only on the signature of interest. However, as in the case of the comparative hydrology study by Berghuijs et al. (2014), the synthesis project by Blöschl et al. (2013) found that similarity of seasonal water balance had a significant influence on the similarity of other signatures too, and may be the strongest indicator used to delineate hydrologically similar regions (Weingartner and Aschwanden, 1992).

The organization of catchments into distinct classes based on hydrologic similarity can open the way to understanding the differences between the classes themselves in terms of the underlying climatic, geologic and landscape controls. The most celebrated example of progress in this area is the empirically derived Budyko curve, famously named after Russian hydrologist Mikhail Budyko. The Budyko curve graphically expresses the long term (or mean annual) water balance, defined by the ratio of long-term average evapotranspiration to precipitation, $E / P$, as a universal function of climatic aridity, the ratio of long-term average potential evaporation to precipitation, $E_{\mathrm{p}} / P$ (Budyko, 1974). The existence of the Budyko curve is usually explained as resulting from a competition between water available (precipitation) and energy available (potential evaporation). In the case of the MOPEX catchments across the United States, Berghuijs et al. (2014) found that the different catchment seasonal water balance (and also vegetation/soil) classes clustered along different segments of the Budyko curve, with little overlap. On the basis of this and other evidence, one can then argue that the competition between water and energy available is mediated by the vegetation that forms through natural selection, highlighting the key role of ecohydrology in hydrologic theory development (Eagleson, 2002; Rodriguez-Iturbe, 2000).

The fact that most of the MOPEX catchments (and other catchments of the world) fall on or about the Budyko curve (leaving a large part of the Budyko space unoccupied) can be seen as an empirical organizing principle, i.e., only some combinations of climate, soil and vegetation characteristics may exist in reality (i.e., are behavioral, Schaefli et al., 2011), indicating a mutual co-dependence through Darwinian coevolution and selection (Eagleson, 2002). Inspired by these observations, in recent times several hydrologists have embarked on a search for physical explanations for the existence of the Budyko curve (Wang and Tang, 2014; Wang et al., 2015; Westhoff et al., 2016). Wang and Tang (2014) and Wang et al. (2015) studied the conceptual bases for empirical models developed by engineers (and geographers) from the 1930s to the 1950s to describe water balances across three different timescales: event, seasonal and annual. These were the SCS curve number method for runoff estimation at the event scale (Mockus, 1949), the abcd model for seasonal (monthly) water balance developed during the Harvard Water Program in the 1960s (Thomas, 1981), and the L'vovich method developed in the former Soviet Union for partitioning of annual precipitation into fast and slow runoff and evaporation (L'vovich, 1979). In the first phase of their work, Wang and Tang (2014) and Wang et al. (2015) showed that all three of them can be described in terms of the so-called proportionality hypothesis, which is long understood as providing the conceptual basis for the SCS curve number method. In the second phase of their work, they showed that the proportionality hypothesis, in turn, can be explained thermodynamically, in terms of the principle of maximum entropy production (MEP). One can thus see that the empirical proportionality hypothesis and the thermodynamic MEP principle appear to provide a vehicle to extend the hydrologic similarity arising from co-evolution across multiple timescales. Admittedly, these are only the first tentative steps in the quest for new theories of hydrology, and yet more creative approaches are needed to extend the notions of similarity and optimality to cover not just the Budyko curve but all other signatures, in order that we fully exploit the order or simplicity that may arise out of Darwinian co-evolution.

The MEP principle, or the equivalent maximum power principle proposed by Kleidon and Renner (2013) and used by Westhoff et al. (2016) to derive the Budyko curve, can be viewed as providing a constraint to the diversity exhibited during Darwinian co-evolution and natural selection, possibly as a mechanism to increase system resilience (Lotka et al., 1922). Furthermore, existence of such physically based organizing principles, valid on a range of timescales as indi- 
cated in the work of Wang et al. (2015), can pave the way for a new generation of behavioral models (Schaefli et al., 2011). This is a promising development for two reasons. On the one hand, it can help constrain model structures inferred from rainfall-runoff data, and on the other hand, it can constrain the parameter combinations allowed for otherwise physically based models that are based on Newtonian mechanics (Li et al., 2014). A unique advantage of the approach adopted by Wang et al. (2015) is that it involved connecting the dots between empirical methods that have been widely used in engineering hydrology for over 50 years, and exploiting the simplicity in these estimation methods that arise from the very co-evolution we are trying to capture in our models (e.g., flood frequency, Guo et al., 2014). Potentially, if continued further, it will have the salutary effect of contributing to fundamental advances while maintaining coherence through avoiding fragmentation (Graham and Dayton, 2002; Blöschl et al., 2013).

\section{Timescale interactions in the Anthropocene: from ecohydrology to socio-hydrology}

The focus of the discussion in the last section was on timescale interactions and the co-evolution of hydrologic and other physical and biologic processes occurring in landscapes. In the otherwise natural catchments considered so far, the dynamic nature of catchment co-evolution was centered on vegetation, its adaptation of itself and its environment through feedbacks between hydrologic and ecologic processes across multiple timescales. This perspective was introduced to assist with developing transferable understanding between places in the course of data-based inference and top-down modeling under otherwise stationary conditions.

As one begins to look to the future, one recognizes the expanding human footprint, including land use and land cover (e.g., vegetation) changes and human interferences in the hydrologic cycle (e.g., water extraction from rivers or groundwater aquifers) and the inevitable acceleration of the timescale interactions. One can no longer count on stationarity for making predictions of catchment responses under these circumstances (Milly et al., 2008; Wagener et al., 2010). Furthermore, over longer periods of time, the timescale interactions must include two-way feedbacks between hydrological (and other Earth system processes) and human-social processes, and the emergent dynamics that result from these. Thus, as we transition from our focus on ecohydrology so far (Eagleson, 2002; Rodriguez-Iturbe, 2000) to the new field of socio-hydrology (Sivapalan et al., 2012), we can recognize both similarities as well as differences between the behaviors of vegetation and humans and, where possible, benefit from lessons learned from the practice of ecohydrology in the past 2 decades.

The co-evolution of water and vegetation does not stop with vegetation adapting to the water and energy balances and vice versa. We noticed that over time vegetation not only adapts itself to the prevailing climate variability and water balance dynamics (even as it modifies it at the same time), but it does so through adapting (or engineering) the landscape or environment around it as well, such as through modifying the soils or topography. Work by Gao et al. (2014) drew an analogy between humans and vegetation and highlighted parallels in water consumption behavior between them. We know humans build storages to cater to periods of drought - in engineering hydrology we estimate the required storage using (for example) the so-called Rippl method (Rippl, 1883). Analogously, Gao et al. (2014) proposed a root storage design method for vegetation, similar to Rippl, where the required storage capacity (with an analogy to root depth) was the between-year maximum of the within-year (seasonal) fluctuation (peak to trough) of soil moisture storage. They extracted this information from the outcomes of the modeling work they had done on a large number of MOPEX catchments across the United States, from which they estimated the pattern of root depth variation between the catchments. They discovered strong correlations between the root depth distributions obtained from such water balance analyses and those independently obtained for the actual vegetation classes found in these catchments. This observation lends strong support to the argument that vegetation adapts itself optimally to the prevailing water balances (seasonal and annual) through adapting itself and adapting its environment so as to, in this case, make maximum use of the water available (see also Troch et al., 2009; Yang et al., 2016; Brantley et al., 2017). These studies confirm and build on the prescient insight of Robert E. Horton, an early pioneer of hydrology who wrote:

Natural vegetation of a region tends to develop to such an extent that it can utilize the largest possible proportion of the available soil moisture supplied by infiltration. - Robert E. Horton (1933)

Note in passing the similarities between Robert Horton's foresight with modern explanatory theories in ecology such as ecological niche theory (Chase, 2011) and niche construction theory (Odling-Smee et al., 2003) that relate, respectively, to how organisms modify themselves and modify their environment.

Admittedly, the examples presented above very much represent a top-down treatment of vegetation adaptation, which I invoked only to make the connection to comparative hydrology, and to highlight how model structures and parameterizations may vary between places through such adaptations. In reality, these broad-scale patterns indicative of co-evolution require further refinement in the context of predictive ecohydrologic theories regarding vegetation adaptation to its environment. One example of this is the vegetation optimality model (VOM) proposed by Schymanski et al. (2009) based on the hypothesis that natural vegetation co-evolves with its 
environment and that over time natural selection leads to a species composition most suited for the given environmental conditions. In VOM this is represented by a trade-off between water loss and carbon gain formulated in terms of the costs associated with the maintenance of roots, water transport tissues and foliage, and the benefits related to the exchange of water for $\mathrm{CO}_{2}$ with the atmosphere, driven by photosynthesis. In VOM the optimal vegetation is taken as the one that maximizes "net carbon profit", i.e., the difference between carbon acquired by photosynthesis and carbon spent on maintenance of organs involved in its uptake. Note however that VOM is just one of many optimality theories that have been proposed in ecohydrology, and is only presented here as an illustrative example. There is increasing availability of data on evaporative fluxes from a large number of flux towers located in different biomes of the world (Thompson et al., 2011a, b) and new remotely sensed datasets on both vegetation cover and evapotranspiration rates over regional scales (Cheng et al., 2011) to complement existing rainfall-runoff data at catchment scales. There is enormous scope for these new datasets to be used to test alternative theories of vegetation adaptation (Brantley et al., 2017) and to provide guidance for the choice of model structures in top-down models, and thus help bridge the current impasse between top-down and bottom-up models.

\subsection{Human-engineered landscapes and catchment water balances}

We now know, at a minimum, how vegetation adapts itself to the water balance and adapts the water balance through its control. Increasingly, humans too interact with catchment water balances, in some ways similar to how vegetation interacts with the natural water balance. Humans extract water directly from rivers or groundwater aquifers to meet their needs, or might build dams across rivers to store water when nature's supply is low, such as during low flow or drought periods. Just as vegetation engineers the landscape to gain and maintain access to water, humans too engineer the landscape (e.g., catchments) to gain and maintain access to water, and to serve other human functions.

Previously hydrologists may only have been interested in the short-term (and local) effects of land use changes and human interferences in the hydrologic cycle to satisfy human needs or functions. With the expansion of the human footprint, they are increasingly concerned with longer-term hydrological changes brought about by human actions and how the changed hydrology then feeds back to generate secondary human reactions. Consequently, it is no longer sufficient, as in the past, to model the hydrology of pristine catchments and add human effects at the end (Wagener et al., 2010). For long-term planning and strategic decision-making purposes, humans must increasingly be treated as an intrinsic part of the catchment's water cycle. This also means that traditional definitions of catchments as topographically defined must be replaced or refined to account for administrative (or governance) units. One can thus imagine how the explicit inclusion of human behavior in hydrologic systems might over long time periods give rise to a co-evolution of water and people. For example, many ancient civilizations established themselves around sources of water, and their success and eventual collapse or dispersal were emergent outcomes of co-evolutionary feedbacks between humans and water (e.g., the Tarim basin in western China, Liu et al., 2014). Under these changing circumstances, one thus moves from ecohydrology, the study of two-way feedbacks between vegetation response and catchment water balance, to socio-hydrology, the new science dealing with two-way feedbacks between human behavior (e.g., water management) and catchment responses (e.g., water balance, flooding dynamics) (Sivapalan et al., 2012, 2014). This extends our earlier Earth system science perspective now to include human-social processes as well.

How far can we push the analogy between vegetation and humans? Unlike vegetation, humans need water not just for their physiological needs (i.e., for drinking), but also for sanitation, and even more so for use in industries, and for food and energy production. This introduces an economic purpose to the use of water, and excessive water extraction for economic uses impacts the environment in adverse ways, and impacts the ability of the environment to produce the ecosystem services (including the delivery of water) that humans also depend on. This introduces the notion of the water-food-energy-environment nexus, and the requirement to make tradeoffs between these various human needs. Two additional factors that enter the management of the waterfood-energy-environment nexus are advances in technology (e.g., infrastructure that enables extraction and transfers of real water between places) and trade (e.g., trade of food and other commodities that depend on water for their production, also known as virtual water trade). Another compounding factor is the role of institutional system of administration, legislation and regulation of water (Sivapalan and Blöschl, 2015). Under these circumstances, human involvement in hydrologic systems in the past has been studied extensively in the context of water resource management, where the focus has been on optimal management (Loucks et al., 2005). Much of this work has worked on the belief that humans are optimizers, assumed to make rational decisions about allocation of resources between various needs, and opting to maximize economic livelihood. However, with the advent of socio-hydrology, hydrologic science has broadened to include the practices and outcomes of water resource management, in the presence of the aforementioned complexities, as themselves subjects for explanation and deeper understanding (Thompson et al., 2013).

A major complexity in understanding and eventually predicting human behavior in the context of water management is human agency (Sanderson et al., 2017). Unlike natural systems, e.g., vegetation, humans can choose among dif- 
ferent modes of thinking and courses of action that impact the natural systems within which they are embedded. A major challenge is that human decision-making shapes, and is shaped by, the cultural contexts within which human societies are embedded. Humans draw upon commonly held values, beliefs and norms to guide their actions, and in turn can collectively change their cultures in the long term (Caldas et al., 2015). Human-water interactions are heavily influenced by differences and/or dynamic changes in human values and norms in respect of their economic livelihood and the environment. Unlike natural systems whose longterm co-evolutionary behavior can be expressed in terms of organizing principles (e.g., vegetation optimality, maximum entropy production), humans can appear to make decisions away from any optimality principles and to violate their own laws (Fig. 7, Sivapalan and Blöschl, 2015). For example, they may extract water from a well, even if it is illegal to do so; or they may choose to live with pollution, away from optimality reasons, giving the impression that unlike vegetation, humans are irrational. The net effects of such human decisions on water systems may manifest as puzzles, paradoxes, and other unintended consequences, nevertheless exhibiting similarities and differences that reflect distinct hydro-climatic, eco-environmental, and socioeconomic features (Sivapalan, 2015; Pande and Sivapalan, 2017). These factors make human-water interactions much more complex and thus add to the already difficult prediction challenges in hydrology (Westerberg et al., 2017). Note, however, that differences highlighted above between natural and human-impacted systems can at least partly be attributed to the timescales of processes relative to the length of available data records. It is tempting to think that, given long enough records, co-evolutionary behavior in respect of coupled human-water system dynamics may indeed be governed by some (as yet unknown) organizing principles. In the end, then, it is a pragmatic choice whether one sees or assumes well-organized patterns within the available data records (Sivapalan and Blöschl, 2005).

It has been suggested that changes in culture and associated values and preferences may be more predictive of human behavior in the context of sustainability than rationality, or utility maximization (Caldas et al., 2015). Examples of human behavior different from utility maximization include (Sivapalan et al., 2014): the peaking in water resource availability as basins develop (peak water paradox, Kandasamy et al., 2014); increasing levee heights in urban environments at the expense of increased flood risk (levee effect, Di Baldassarre et al., 2013); increasing agriculture water consumption in spite of irrigation efficiency improvements (irrigation efficiency paradox) (Scott, 2011); and over-exploitation of coastal aquifers at the risk of causing saltwater intrusion (Chang and Clement, 2012). An example of non-optimal behavior in the context of coupled human-water system dynamics is lock-in or path dependence, which is one explanation offered for the collapse of the Maya civilization (Kuil
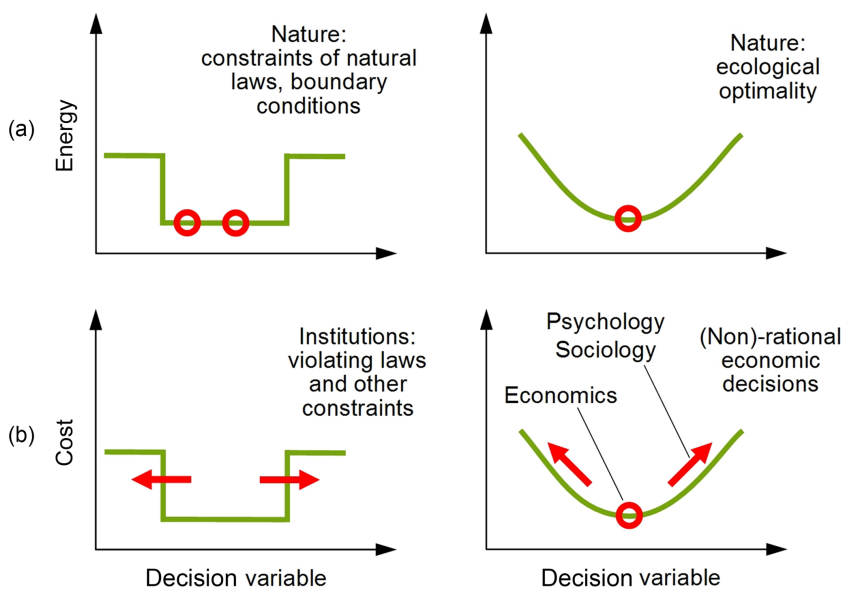

Figure 7. (a) Natural systems follow constraints and optimality laws; (b) Human systems may violate constraints and make irrational decisions away from optimality (taken from Sivapalan and Blöschl, 2015).

et al., 2016). A more recent example of lock-in is the selfreinforcing action of the people of the Netherlands since the 11th century to drain their naturally peaty soils, leading to land subsidence, which ultimately led to the invention of the famous Gouda cheese, since the resulting low-lying areas that these actions produced were only suitable for dairy farming (Erkens et al., 2016). The science of socio-hydrology aims to explain these kinds of phenomena arising from twoway feedbacks associated with coupled human-water system dynamics, and to develop a generalized understanding that can connect diverse phenomena across many places and times (Sivapalan and Blöschl, 2015). There is still room for predictions in this new era of socio-hydrology: but given the difficulties of dealing with human agency and complex human behavior, the focus is not on predicting what will happen at a future prescribed time, as it is in traditional hydrology, but on mapping out the possibility space of future trajectories of system co-evolution (see Fig. 8, Srinivasan et al., 2017).

\section{Engineering hydrology to Earth system science: from Newton to Darwin to Wegener}

There is no question that there has been a fundamental transformation of hydrology in the past 50 years. My goal in this narrative has been to connect the dots and draw up a continuous thread through what I thought were major milestones in the evolution of the science. Hydrology (for me) started as engineering hydrology, addressing rather simple, well-defined problems (e.g., what is the 100-year flood?). Over time, problems became increasingly complex, such as the need to predict the effects of land use changes or climate change (e.g., on 100-year floods), which required more process-based approaches invoking Newtonian mechanics. Even as the ability to make predictions using such physi- 


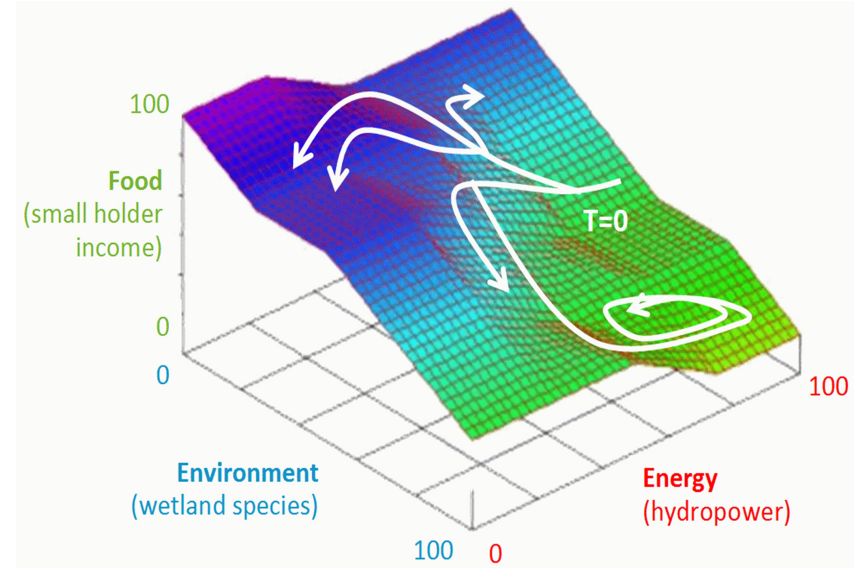

Figure 8. Trajectories illustrating the future possibility space that may be predicted by a socio-hydrological model addressed to management of the water-food-energy-environment nexus (taken from Srinivasan et al., 2017).

cally based models advanced, they encountered limitations due to unknown (and unknowable) heterogeneity of landscapes, and the lack of understanding of process interactions in the time domain, including how catchments functioned as whole ecosystems. Conceptual or functional models based on data-based inference partially helped to overcome these limitations, but they in turn suffered from heavy dependence on data, and the absence of holistic theories of catchment responses and ecosystem functioning.

The seeming impasse between the two approaches to predictions, mechanistic and functional, has motivated hydrologists to broaden the research from the traditional focus on estimation and prediction towards understanding, explanation and discovery. The shift towards understanding and explanation does not signify a lack of commitment to applications of hydrology, however. The goal of hydrology as use-inspired basic science (Stokes, 1997; Thompson et al., 2013) remains, which is to generate the basic understanding necessary to address the complex water sustainability or management problems that appear on the horizon. The nature and role of predictions have also evolved as problems become more complex and highly inter-disciplinary. The change in focus towards understanding and explanation is contributing to two major shifts in hydrology research. The first is increased attention to phenomena, emergent patterns that arise through process interactions across timescales and space scales. Numerical models are increasingly now used to test hypotheses about how these phenomena may have arisen and thus contribute towards accumulation of knowledge and understanding. The second major shift is towards comparative hydrology, i.e., comparative studies across gradients of climate, geology and human impacts. This is a Darwinian approach, which seeks to develop new insights and theories about catchments, as consisting of components that have co- evolved together, and to learn from the common history of their co-evolution.

Given this co-evolutionary perspective, hydrological problems needed to be framed broadly as inter-disciplinary problems that extend beyond the study of water flows in landscapes. In natural landscapes we are increasingly concerned with water flow processes interacting with and feeding back on land-forming (e.g., pedogenesis, soil erosion and deposition) and life-sustaining (e.g., biogeochemical, ecological) processes. With the expanding human footprint, hydrology also has to deal with vastly complex social processes. An example (one of many) of a new problem that hydrologists have to deal with in this context is the nature of interactions between people and droughts that might lead to exacerbation of water shortages (Apurv et al., 2017), conflicts, human migration, and even collapse (Kuil et al., 2016). This places hydrology squarely within the realm of Earth system science, with an alternate set of problems, questions, and study tools. With the broadening of the science there is increasing attention to a diversity of emergent phenomena that arise in the context of co-evolution of climate, soils, vegetation, and now humans.

Exploring phenomena of all kinds - defined as interesting catchment responses or ecosystem functioning with no obvious or immediate explanation - and asking how they came about, which is the scientific method practiced and perfected over centuries, is increasingly the main focus of most hydrological investigations. Bronowski (1956) describes the majesty of the scientific method in these terms:

\begin{abstract}
All science is the search for unity in hidden likenesses... The progress of science is the discovery at each step of a new order which gives unity to what had long seemed unlike... For order does not display itself of itself; if it can be said to be there at all, it is not there for the mere looking... order must be discovered and, in a deep sense, it must be created. What we see, as we see it, is mere disorder. - Bronowski (1956)
\end{abstract}

Increasingly, in a co-evolutionary context, one can adopt three different kinds of approaches to generate and study phenomena of interest to us. These may be framed as historical hydrology, comparative hydrology and process hydrology. Historical hydrology generates phenomena in the form of emergent dynamics in the time domain arising from timescale interactions. Comparative hydrology generates patterns of catchment responses between different catchments or places. Process hydrology generates patterns at a single place, resulting from process interactions in space (or space-time).

The evolution of the science and the growth of hydrological understanding over the past 50 years have benefited from the use of a combination of Newtonian and Darwinian approaches to address and explore increasingly complex prediction problems and emergent phenomena. The Newtonian 


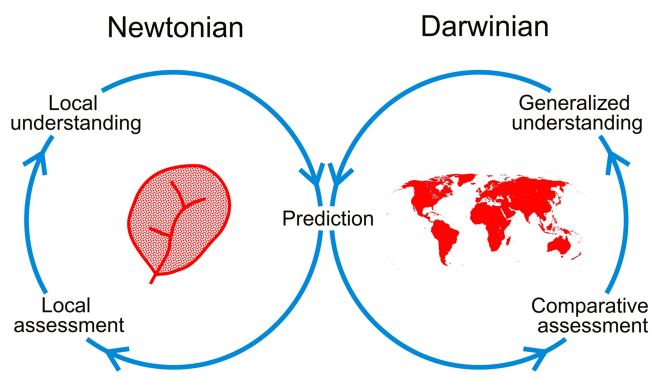

Figure 9. Newtonian-Darwinian synthesis: relative contributions of Newtonian (learning from individual catchments through detailed studies) and Darwinian (learning from a population of catchments through comparative studies) approaches (taken from Blöschl et al., 2013).

approach benefits from the fact that it is based on universal laws of mass, momentum and energy balances, with clear causality. It gains predictive power through advances in observing and understanding processes, and approaches to account for landscape heterogeneity and the resulting complexity of flow pathways and residence times. Yet it loses effectiveness in making general predictions by not being able to fully account for process interactions and feedbacks and parameter co-dependency that manifest in catchments through co-evolutionary processes. The legacy of past coevolutionary processes in landscapes and their interconnections over long time periods lead to complex emergent spatial patterns and temporal dynamics. So an alternative approach to studying patterns and dynamics arising from such coevolution is to study many catchments comparatively, treating them as legacies of past co-evolution, which is the Darwinian way. In short, the Newtonian approach generalizes by discovering universal laws governing particular processes through experimentation, inductive reasoning and through mathematical derivations, whereas the Darwinian approach generalizes by recognizing emergent phenomena through comparative analyses across places and then seeking explanations for how they came about (Guo et al., 2014). Of course, Newtonian and Darwinian methods are complementary to each other, and progress in terms of new theories of hydrology and improvements in our ability make future predictions everywhere will require a synthesis of these two approaches (Fig. 9) (Harte, 2002; Blöschl et al., 2013).

\subsection{Crystal balling the future: from comparative hydrology to regional process hydrology}

One of the benefits of developing a historical narrative, as I have done here, is that it provides a perspective view (rightly or wrongly) of where we have come from and where we may be (or should be) headed. I will therefore be remiss if I do not use the "crystal ball" that I have created in my mind based on this review to say something about what is in store for hydrology in the coming decade(s). In doing so I stand to benefit from a perspective that has helped me most to organize my narrative: this is the scale perspective. The issue of scale has been at the heart of most of the difficulties hydrologists have had in terms of developing new theories and advancing predictions. If at all we have made any progress in hydrology, this may be attributed to advances we have made in addressing scale issues (Blöschl and Sivapalan, 1995; Blöschl et al., 2013). So now, going over the progress we have made in hydrology over the last 50 years (Sivapalan and Blöschl, 2017), one cannot but recognize the change in focus from time during the empirical era (engineering hydrology), to space (Newtonian mechanics) during the process era, and back to time (Darwinian comparative hydrology) in the current co-evolutionary era. By induction, this symmetry tells me that even while remaining within the co-evolutionary framework, the next major change in focus is likely to be (or even should be) to go back to space, and to space-time.

It occurs to me that for far too long we hydrologists (or far too many of us) have focused on catchments as isolated objects, with an exclusive focus on their rainfall-runoff (inputoutput) transformations. Even in the context of comparative hydrology, we have continued to treat them as spatially distinct and independent objects, even while acknowledging or exploiting their common or similar co-evolutionary history. Clearly this is limiting, in terms of the phenomena that we can explore, and the kinds of predictions we increasingly have to make at larger spatial scales. If we extend the size of the study domain from isolated catchments to a whole region, then in many cases the catchments present within the region have spatial connectivity, as well as a common history. Catchments within a region can be connected to each other in three ways: downwind movement of water in the atmosphere, downstream water movement through surface pathways (e.g., rivers), and subsurface water movement (e.g., regional aquifers) from recharge areas in the mountains towards the ocean, leading to groundwater outcropping in streams, lakes and wetlands, and to estuaries and deltas in coastal regions. In this way there is a continual transformation across the region in the nature of interactions between atmospheric, surface and subsurface pathways of water, producing unique waterscapes. This inexorably takes us into a new field that we might as well call regional process hydrology. Just as a single catchment is viewed as a co-evolved ecosystem, owing to the co-evolution of different components (i.e., mountain range, headwater catchments, river network and floodplains, wetlands and estuaries), the region too needs to be looked at and managed as a whole ecosystem. An example of such a region satisfying these features is the arid Kaidu-Kongqi River basin in western China, which is supplied by snowmelt and glacier melt in its headwaters, feeding an extensive oasis and the terminal Bosten Lake, both of which support a thriving agricultural community in the midst of a vast desert (Fig. 10).

The Kaidu-Konqi River basin, and many others like it around the world (e.g., the Indus River basin in present- 


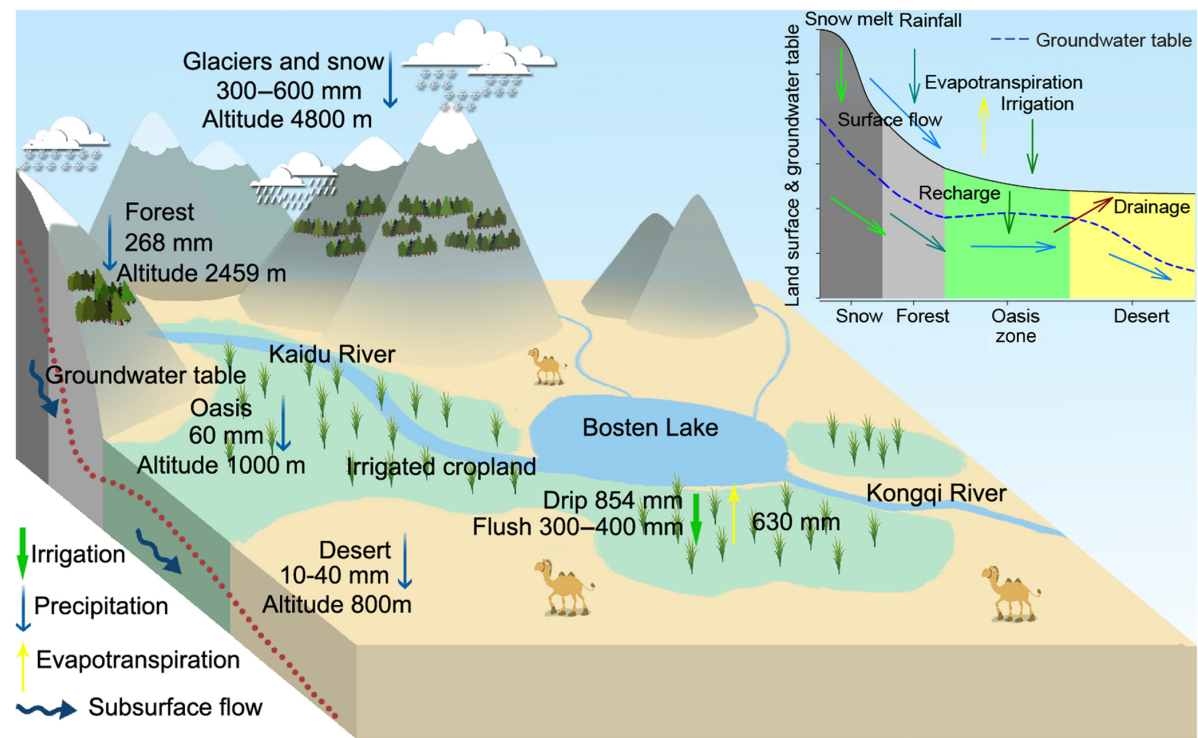

Figure 10. Regional process hydrology: schematic of the regional hydrologic cycle and waterscape in the Kaidu-Kongqi River basin, part of the much larger Tarim River basin, Xingjiang Province, in western China (taken from Zhang et al., 2014).

day Pakistan, the Cauvery River basin in southern India), have been cradles of human civilization that have waxed and waned as a result of long-term, large-scale climatic changes, as well as human alterations of their waterscapes and overexploitation of land and water resources (Liu et al., 2014). The complexity of water balances and long-term water management problems across such regions cannot be tackled by studying a few isolated catchments. As we begin to look at a region as a whole, the proposed regional outlook opens up new possibilities to advance hydrology, with altogether new emergent phenomena that arise through interactions of the atmosphere, land surface and regional groundwater aquifers, including the waterscapes that form as a result. This regional hydrology focus can also bring about the overdue unification of surface (catchment) hydrology with groundwater hydrology, and extensions of ecohydrology and socio-hydrology, to explore interesting, regional-scale phenomena.

I am not the first one to make the case for regional process hydrology, however. Tom Dunne, in his famous Abel Wolman Lecture (Dunne, 1998), called for a renewed focus on research targets at large spatial scales (i.e., regional) that are "of broad significance and might attract sustained interest from scientists in other fields and society at large". There is already much activity in regional process hydrology that is beginning to bring surface and/or groundwater hydrologists together with atmospheric scientists, with a focus on modeling, large-scale synergistic observations and data-model syntheses (Fan, 2015; Hipsey et al., 2015; Maxwell et al., 2015; Blöschl et al., 2017). Echoing Dunne (1998) himself, my main argument is to go beyond mere descriptions or narratives as we may have done in the past, and to reinforce the focus on phenomena, now regional-scale phenomena, and on process explanation and discovery, as a prelude to eventual predictions at these scales. The relevant processes of interest occur at all space scales and timescales, and are not limited to just small scales, and emergent phenomena arise out of these multi-scale (space, space-time) process interactions. Both Newtonian (bottom-up reductionist) and Darwinian (top-down functional) approaches and their synthesis retain currency, including the use of coarse-grained models to explore observed phenomena. So this is regional process hydrology that requires a whole system synergistic perspective.

Within the spirit of use-inspired basic science (Stokes, 1997; Thompson et al., 2013) the move towards regional hydrology also coincides with the evolution of the nature of water management problems that will be faced in the emergent Anthropocene. Thompson et al. (2013) presented several examples of anticipated century-scale trends in the main hydrologic drivers that will impact humanity in the future. These emerging future challenges include changing demography (Wagener et al., 2010), warming climate (Vörösmarty et al., 2000), rapid urbanization (Di Baldassarre et al., 2010), changing rainfall variability (Blöschl et al., 2017), loss of freshwater resources due to rising sea levels and saltwater intrusion (Chang et al., 2011), and globalization of water systems through real and virtual water trade (Konar et al., 2016). One can anticipate a range of water-related problems and secondary effects that will emerge in response to these drivers. Increasingly these problems will manifest at regional (and global) scales and can no longer be addressed through the study of individual, isolated catchments. Instead, we need a regional, increasingly global, approach to the study of these problems. Each of these problems is likely to draw attention 


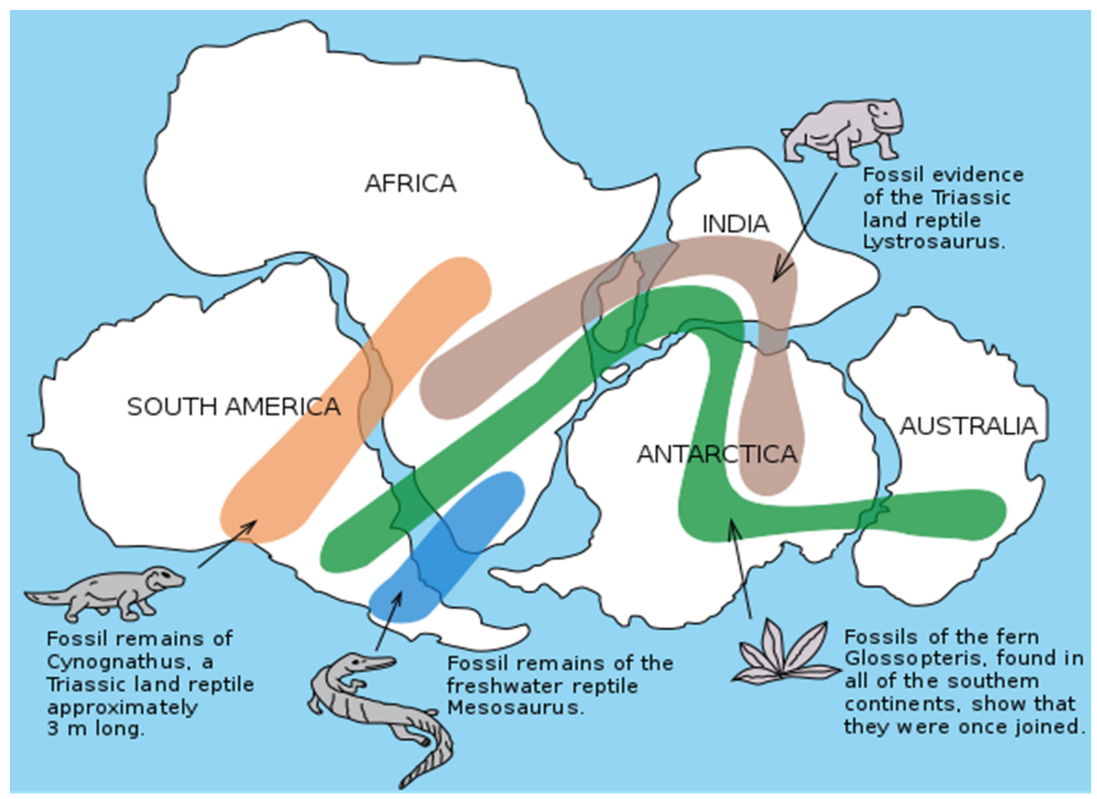

Figure 11. Connecting the dots: schematic describing the fossil patterns across continents that were the basis upon which Alfred Wegener proposed his continental drift theory: https://en.wikipedia.org/wiki/Alfred_Wegener (accessed on 28 October 2017).

to an array of emergent phenomena that manifest at the regional scale, and associated science questions, which could be the basis for the next major exciting phase of research in scientific hydrology.

The extension of the co-evolutionary perspective in space towards the regional scale takes us further from even Darwinian comparative hydrology (of isolated catchments) to the kind of approach adopted by Alfred Wegener, which eventually led to the discovery of plate tectonics. During his extensive journeys around the world, Wegener evaluated multiple variables (e.g., fossil records, rock types) across several continental regions with which he drew coherent spatial connections across places to support his reasoning on the continental drift (Fig. 11). Such an approach becomes feasible in hydrology too with the extraction of spatial patterns of multiple variables (e.g., climate, hydrology, vegetation, animals, people) across large regions, which could then serve as the basis for breakthroughs in understanding of regional water balance, and the co-evolutionary dynamics of climate, soils, vegetation, and human settlements that contribute to the formation of regional waterscapes. Much can be learned from studying spatial teleconnections (especially upstream-downstream) through remote sensing techniques and regional models (Guan et al., 2014), and how they impact and in turn are impacted by human alterations to landscapes and watercourses. Even though much of this is necessarily place-based, unique to particular regions, there is also much that can be transferred to other regions.

As the world becomes inter-connected through improvements in communications technology, trade, and the movement of people and ideas, along with global teleconnections in the climate system, it is increasingly necessary to go even further and treat the world as a single inter-connected system (Eagleson, 1986; Lall, 2014). Within the one-world system, anticipated global changes are likely to give rise to yet more complex phenomena manifesting as new and challenging water-related problems at both regional and global scales. This will require truly global and long-term vision and passion, the type of passion that led Alfred Wegener to discover continental drift and to open up the debate that ultimately led to the development of the theory of plate tectonics. Achieving this grand vision in hydrology will probably take us into what we have called the globalization era (Sivapalan and Blöschl, 2017), with a grand synthesis of global hydrology integrated with economics and climate science, as also concluded in an earlier review by Bierkens (2015). These are exciting times to be a hydrologist.

\subsection{Lessons from Newton, Darwin, and Wegener: connecting the dots}

This paper being an outgrowth of my Wegener Medal Lecture, in conclusion, I feel duty bound to reflect on the lessons we as hydrologists can learn from the methods adopted by not only Wegener, but also Newton and Darwin, and their contributions to science and the scientific pursuit. The ultimate goal in science is to "connect the dots", i.e., "to find order in disorder" (Bronowski, 1956), which should be the ultimate goal in hydrologic science too. It is in this spirit that Dooge (1986) exhorted us "to look for hydrological laws" and Klemeš (1986) warned against the "dilettantism" that results from failure to distinguish between science and applica- 
tions of the science, as between hydrograph fitting and hydrological understanding. In his paper on "a hydrologic perspective", Klemeš (1988) emphasized the primacy of process understanding over techniques, i.e., the unravelling of the puzzles of the water cycle over the kinds of technologies that are adopted to solve societal problems, and warned against defining catchments merely by the different techniques that we might use from time to time to analyze them as engineering hydrologists. Regardless of the different methods they may have used, Newton, Darwin and Wegener, were ultimately giants in the art of connecting the dots, and we stand to benefit from the legacy they have left behind. Methods may come and go, but success depends on us not becoming slaves to the methods but treating them as necessary tools for a higher purpose, i.e., advancing science through connecting the dots.

The method-oriented (wo)man is shackled; the problem-oriented (wo)man is at least reaching freely toward what is most important... willing repeatedly to put aside his(her) last methods and teach him(her)self new ones. - Adapted from Platt (1964).

Acknowledgements. This paper is an outgrowth from the Alfred Wegener Medal Lecture I gave at the General Assembly of the European Geosciences Union in April 2017. I thank the EGU for bestowing this honor on me and for giving me the opportunity to publish this paper in HESS. My thoughts on the evolution of hydrology came about through interactions with many students and colleagues over the years. They gained potency through my involvement in three community activities: the Predictions in Ungauged Basins (PUB) initiative, the University of Illinois Hydrologic Synthesis activity, and the Predictions under Change activity, which morphed into the Socio-hydrology movement, and both contributed to the launch of the IAHS Panta Rhei initiative. I am proud of the global hydrology community I served and learned from.

The paper has benefited from suggestions and comments I received from Keith Beven, Marc Bierkens, Günter Blöschl, Prabhakar Clement, John Ding, Markus Hrachowitz, Hongyi Li, Saket Pande, Jose Salinas, Majid Shafiee-Jood, Stan Schymanski, Richard Silberstein, Kevin Wallington, Dingbao Wang and Erwin Zehe. I am extremely grateful for their inputs, but in the final analysis, this is a personal account, and I am ultimately responsible for any errors of omission and commission that remain.

In closing, I bring up a line from Kondraiventhan, an anthology of poems written by legendary Tamil poetess Avvaiyar, who lived in southern India c. 1000 years ago. It reads:

\section{எண்ணும் எழுத்தும் கண் எனத் தகும்}

Numbers (mathematics) and letters (language) are like our twin eyes

(i.e., our windows to the world)
These immortal words of Avvaiyar help me to celebrate the memory of two teachers I had at Hartley College, Point Pedro, Sri Lanka, the high school from which I entered university. S. Ratnasabapathy taught me Mathematics and S. S. Manuelpillai taught English. They both also shaped my intellectual outlook and the way to approach personal and professional challenges. It is not an exaggeration to say that the discipline, persistence and pursuit of excellence they instilled in me continue to guide me more than 50 years after they had taught me.

Edited by: Erwin Zehe

Reviewed by: Marc Bierkens and Keith Beven

Competing interests. The author declares that he has no conflict of interest.

\section{References}

Abbott, M. B., Bathurst, J. C., Cunge, J. A., O'Connell, P. E., and Rasmussen, J.: An introduction to the European Hydrological System-Systeme Hydrologique Europeen, "SHE", 1: history and philosophy of a physically-based, distributed modelling system, J. Hydrol., 87, 45-59, 1986.

Apurv, T., Sivapalan, M., and Cai, X.: Understanding the role of climate characteristics in drought propagation, Water Resour. Res., 53, 9304-9329, https://doi.org/10.1002/2017WR021445, 2017.

Atkinson, S., Woods, R. A., and Sivapalan, M.: Climate and landscape controls on water balance model complexity over changing time scales, Water Resour. Res., 38, 1314, https://doi.org/10.1029/2002WR001487, 2002.

Band, L. and Wood, E. F.: Strategies for large-scale, distributed hydrologic simulation, Appl. Math. Comput., 27, 23-37, 1988.

Bear, J.: Dynamics of Fluids in Porous Media, Elsevier, Amsterdam, 764 pp., 1972.

Berghuijs, W. R., Sivapalan, M., Woods, R. A., and Savenije, H. H. G.: Patterns of similarity of seasonal water balance: A window into streamflow variability over a range of timescales, Water Resour. Res., 50, 5638-5661, https://doi.org/10.1002/2014WR015692, 2014.

Bergström, S.: Development and Application of a Conceptual Runoff Model for Scandinavian Catchments, Norrköping: SMHI, Report No. RHO 7, 1976.

Beven, K.: Kinematic subsurface stormflow, Water Resour. Res., 17, 1419-1424, 1981.

Beven, K.: Searching for the Holy Grail of scientific hydrology: $Q t=(S, R, \Delta t) A$ as closure, Hydrol. Earth Syst. Sci., 10, 609618, https://doi.org/10.5194/hess-10-609-2006, 2006.

Beven, K. and Germann, P.: Macropores and water flow in soils, Water Resour. Res., 18, 1311-1325, 1982.

Beven, K. J.: Changing ideas in hydrology: the case of physically based models, J. Hydrol., 105, 157-172, 1989.

Beven, K. J.: Uniqueness of place and process representations in hydrological modelling, Hydrol. Earth Syst. Sci., 4, 203-213, https://doi.org/10.5194/hess-4-203-2000, 2000. 
Beven, K. J.: Rainfall-Runoff Modelling: The Primer, 360 pp., John Wiley, Chichester, UK, 2012.

Beven, K. J.: What we see now: eventpersistence and the predictability of hydro-ecogeomorphological systems, Ecol. Model., 298, 4-15, https://doi.org/10.1016/j.ecolmodel.2014.07.019, 2015.

Beven, K. J.: Facets of uncertainty: epistemic uncertainty, nonstationarity, likelihood, hypothesis testing, and communication, Hydrol. Sci. J., 61, 1652-1665, 2016.

Beven, K. J. and Binley, A. M.: The future of distributed models: model calibration and uncertainty prediction, Hydrol. Process., 6, 279-298, 1992.

Beven, K. J. and Cloke, H. L.: Comment on "Hyperresolution global land surface modeling: Meeting a grand challenge for monitoring Earth's terrestrial water" by E. F. Wood et al., Water Resour. Res., 48, W01801, https://doi.org/10.1029/2011WR010982, 2012.

Beven, K. J. and Kirkby, M. J.: A physically-based, variable contributing area model of basin hydrology, Hydrol. Sci. Bull., 24, 43-69, 1979.

Bierkens, M. F. P.: Global hydrology: State, trends, and directions, Water Resour. Res., 51, 4923-4947, https://doi.org/10.1002/2015WR017173, 2015.

Black, P. E.: Watershed functions, J. Am. Water Resour. Assoc., 33, 1-11, https://doi.org/10.1111/j.1752-1688.1997.tb04077.x, 1997.

Blöschl, G. and Sivapalan, M.: Scale issues in hydrological modelling - A review, Hydrol. Process., 9, 251-290, 1995.

Blöschl, G., Grayson, R. B., and Sivapalan, M.: On the representative elementary area (REA) concept and its utility for rainfallrunoff modelling, Hydrol. Process., 9, 313-330, 1995.

Blöschl, G., Sivapalan, M., Wagener, T., Viglione, A., and Savenije, H. H. G.: Runoff Prediction in Ungauged Basins - Synthesis across Processes, Places and Scales, Cambridge University Press, Cambridge, UK, 500 pp., 2013.

Blöschl, G., Blaschke, A. P., Broer, M., Bucher, C., Carr, G., Chen, X., Eder, A., Exner-Kittridge, M., Farnleitner, A., Flores-Orozo, A., Haas, P., Hogan, P., Kazemi Amiri, A., Oismüller, M., Parajka, J., Silasari, R., Stadler, P., Strauss, P., Vreugdenhil, M., Wagner, W., and Zessner, M.: The Hydrological Open Air Laboratory (HOAL) in Petzenkirchen: a hypothesis-driven observatory, Hydrol. Earth Syst. Sci., 20, 227-255, https://doi.org/10.5194/hess20-227-2016, 2016.

Blöschl, G., Hall, J., Parajka, J., Perdigão, R. A. P., Merz, B., Arheimer, B., and Živković, N.: Changing climate shifts timing of European floods, Science, 357, 588-590, doi.org/10.1126/science.aan2506, 2017.

Brantley, S. L., Eissenstat, D. M., Marshall, J. A., Godsey, S. E., Balogh-Brunstad, Z., Karwan, D. L., Papuga, S. A., Roering, J., Dawson, T. E., Evaristo, J., Chadwick, O., McDonnell, J. J., and Weathers, K. C.: Reviews and syntheses: On the roles trees play in building and plumbing the critical zone, Biogeosciences, 14, 5115-5142, https://doi.org/10.5194/bg-14-5115-2017, 2017.

Bronowski, J.: Science and Human Values, 94 pp., Julian Messner Inc., New York, 1956.

Brunner, P. and Simmons, C. T.: HydroGeoSphere: a fully integrated, physically based hydrological model, Groundwater, 50, 170-176, 2012.

Budyko, M. I.: Climate and Life, 508 pp., Academic, NY, 1974.
Burt, T. P. and McDonnell, J. J.: Whither field hydrology? The need for discovery science and outrageous hydrological hypotheses, Water Resour. Res., 51, 5919-5928, 2015.

Caldas, M., Sanderson, M. R., Mather, M., Daniels, M. D., Bergtold, J. S., Aistrup, J., Heier Stamm, J. L., Haukos, D., DouglasMankin, K., Sheshukov, A. Y., and Lopez-Carr, D.: Endogenizing culture in sustainability science research and policy, P. Natl. Acad. Sci. USA, 112, 8157-8159, 2015.

Chang, S. W., Clement, T. P., Simpson, M. J., and Lee, K. K.: Does sea-level rise have an impact on saltwater intrusion?, Adv. Water Resour., 34, 1283-1291, https://doi.org/10.1016/j.advwatres.2011.06.006, 2011.

Chang, S. W. and Clement, T. P.: Experimental and numerical investigation of saltwater intrusion dynamics in flux controlled groundwater systems, Water Resour. Res., 48, W09527, https://doi.org/10.1029/2012WR012134, 2012.

Chase, J. M.: Ecological niche theory, in: The Theory of Ecology, edited by: Scheiner, S. M. and Willig, M. R., University of Chicago Press, Chicago, 93-108, 2011.

Cheng, L., Xu, Z., Wang, D., and Cai, X.: Assessing interannual variability of evapotranspiration at the catchment scale using satellite-based evapotranspiration data sets, Water Resour. Res., 47, W09509, https://doi.org/10.1029/2011WR010636, 2011.

Chow, V. T.: Handbook of Applied Hydrology, McGraw-Hill, New York, 1376 pp., 1964.

Chow, V. T., Maidment, D. R., and Mays, L.: Applied Hydrology, McGraw-Hill, New York, 572 pp., 1988.

Clark, M. P., Nijssen, B., Lundquist, J., Kavetski, D., Rupp, D., Woods, R., Gutmann, E., Wood, A., Brekke, L., Arnold, J., Gochis, D., and Rasmussen, R.: A unified approach to process-based hydrologic modeling. Part 1: Modeling concept, Water Resour. Res., 51, 2498-2514, https://doi.org/10.1002/2015WR017198, 2015.

Clark, M. P., Bierkens, M. F. P., Samaniego, L., Woods, R. A., Uijlenhoet, R., Bennett, K. E., Pauwels, V. R. N., Cai, X., Wood, A. W., and Peters-Lidard, C. D.: The evolution of process-based hydrologic models: historical challenges and the collective quest for physical realism, Hydrol. Earth Syst. Sci., 21, 3427-3440, doi.10.5194/hess-21-3427-2017, 2017.

Clement, T. P.: Complexities in hindcasting models - when should we say enough is enough?, Ground Water, 49, 620-629, https://doi.org/10.1111/j.1745-6584.2010.00765.x, 2011.

Crawford, N. H. and Linsley, R. K.: Digital Simulation in Hydrology: Stanford Watershed Model IV, Technical Report No. 39, Department of Civil Engineering, Stanford University, 210 pp., 1966.

Davies, P. C. W.: Why is the physical world so comprehensible?, CTNS Bulletin 12, 16-21, 1992.

Di Baldassarre, G., Montanari, A., Lins, H., Koutsoyiannis, D., Brandimarte, L., and Blöschl, G.: Flood fatalities in Africa: From diagnosis to mitigation, Geophys. Res. Lett., 37, L22402, https://doi.org/10.1029/2010GL045467, 2010.

Di Baldassarre, G., Viglione, A., Carr, G., Kuil, L., Salinas, J. L., and Blöschl, G.: Socio-hydrology: Conceptualising humanflood interactions, Hydrol. Earth Syst. Sci., 17, 3295-3303, https://doi.org/10.5194/hess-17-3295-2013, 2013.

Didszun, J. and Uhlenbrook, S.: Scaling of dominant runoff generation processes: Nested catchments approach us- 
ing multiple tracers, Water Resour. Res., 44, W02410, https://doi.org/10.1029/2006WR005242, 2008.

Dooge, J. C. I.: Looking for hydrologic laws, Water Resour. Res., 22, 46S-58S, 1986.

Dooge, J. C. I.: History of Hydrology Film Interviews: J. C. I. Dooge Interviewed by D. R. Dawdy, Amer. Geophys. Union, available at: https://hydrology.agu.org/ resources/history-of-hydrology-film-interviews, (last access: 1 March 2018) 1995.

Dunne, T.: Field studies of hillslope flow processes, Chapter 7, in: Hillslope Hydrology, edited by: Kirkby, M. J., Wiley, London, 227-293, 1978.

Dunne, T.: Wolman Lecture: Hydrologic science in landscapes on a planet in the future, in: Hydrologic Sciences: Taking Stock and Looking Ahead, Water Science and Technology Board, National Research Council, 10-43, Natl. Acad. Press, Washington, D.C., 1998.

Dunne, T. and Black, R. D.: Partial area contributions to storm runoff in a small New England watershed, Water Resour. Res., 6, 1296-1311 1970.

Eagleson, P. S.: Dynamic Hydrology, McGraw-Hill, New York, 462 pp., 1970.

Eagleson, P. S.: The emergence of global-scale hydrology, Water Resour. Res., 22, 6S-14S, 1986.

Eagleson, P. S.: Ecohydrology: Darwinian Expression of Vegetation Form and Function, Cambridge Univ. Press, Cambridge, UK, 345 pp., https://doi.org/10.1017/CBO9780511535680, 2002.

Erkens, G., van der Meulen, M. J., and Middelkoop, H.: Double trouble: subsidence and $\mathrm{CO}_{2}$ respiration due to 1,000 years of Dutch coastal peatlands cultivation, Hydrogeol. J., 24, 551-568, https://doi.org/10.1007/s10040-016-1380-4, 2016.

Falkenmark, M. and Chapman, T.: Comparative Hydrology, UNESCO, Paris, 479 pp., 1989.

Fan, Y.: Groundwater in the Earth's critical zone: Relevance to large-scale patterns and processes, Water Resour. Res., 51, 30523069, https://doi.org/10.1002/2015WR017037, 2015.

Fan, Y. and Bras, R. L.: On the concept of a representative elementary area in catchment runoff, Hydrol. Process., 9, 821-832, 1995.

Fang, K. and Shen, C.: Full-flow-regime storage-streamflow correlation patterns provide insights into hydrologic functioning over the continental US, Water Resour. Res., 53, 8064-8083, https://doi.org/10.1002/2016WR020283, 2017.

Farmer, D., Sivapalan, M., and Jothityangkoon, C.: Climate, soil and vegetation controls upon the variability of water balance in temperate and semi-arid landscapes: Downward approach to hydrological prediction, Water Resour. Res., 39, 1035, https://doi.org/10.1029/2001WR000328, 2003.

Fenicia, F., Kavetski, D., and Savenije, H. H. G.: Elements of a flexible approach for conceptual hydrological modeling: 1. Motivation and theoretical development, Water Resour. Res., 47, W11510, https://doi.org/10.1029/2010wr010174, 2011.

Freeze, R. A. and Harlan, R. L.: Blueprint for a physically-based, digitally-simulated hydrologic response model, J. Hydrol., 9, 237-258, 1969.

Freeze, R. A.: Streamflow generation, Rev. Geophys. Space Phys., 12, 627-647, 1974.

Freeze, R. A.: A stochastic conceptual analysis of rainfall-runoff processes on a hillslope, Water Resour. Res., 6, 391-408, 1980.
Gaál, L., Szolgay, J., Kohnová, S., Parajka, J., Merz, R., Viglione, A., and Blöschl, G.: Flood timescales: Understanding the interplay of climate and catchment processes through comparative hydrology, Water Resour. Res., 48, W04511, https://doi.org/10.1029/2011WR011509, 2012.

Gao, H., Hrachowitz, M., Schymanski, S. J., Fenicia, F., Sriwongsitanon, N., and Savenije, H. H. G.: Climate controls how ecosystems size the root zone storage capacity at catchment scale, Geophys. Res. Lett., 41, 7916-7923, https://doi.org/10.1002/2014GL061668, 2014.

Gelhar, L. W. and Axness, C. L.: Three-dimensional stochastic analysis of macrodispersion in aquifers, Water Resour. Res., 19, 161180, https://doi.org/10.1029/WR019i001p00161, 1983.

Gharari, S., Hrachowitz, M., Fenicia, F., and Savenije, H. H. G.: Hydrological landscape classification: investigating the performance of HAND based landscape classifications in a central European meso-scale catchment, Hydrol. Earth Syst. Sci., 15, 3275-3291, https://doi.org/10.5194/hess-15-3275-2011, 2011.

Graham, M. H. and Dayton, P. K.: On the evolution of ecological ideas: Paradigms and scientific progress, Ecology, 83, 14811489, 2002.

Grayson, R. B., Moore, I. D., McMahon, T. A.: Physically based hydrologic modeling: 2. Is the concept realistic?, Water Resour. Res., 28, 2659-2666, https://doi.org/10.1029/92WR01259, 1992.

Guan, K., Wood, E. F., Medvigy, D., Kimball, J., Pan, M., Caylor, K. K., Sheffield, J., Xu, X., and Jones, M. O.: Terrestrial hydrological controls on land surface phenology of African savannas and woodlands. J. Geophys. Res.-Biogeosci., 119, 1652-1669, https://doi.org/10.1002/2013JG002572, 2014.

Guo, J., Li, H.-Y., Leung, L. R., Guo, S., Liu, P., and Sivapalan, M.: Links between flood frequency and annual water balance behaviors: A basis for similarity and regionalization, Water Resour. Res., 50(, 937-953, https://doi.org/10.1002/2013WR014374, 2014.

Harman, C. J. and Sivapalan, M.: Similarity framework to assess controls on subsurface flow dynamics in hillslopes, Water Resour. Res., 45, W01417, https://doi.org/10.1029/2008WR007067, 2009.

Harman, C. J., Rao, P. S. C., Basu, N. B., McGrath, G. S., Kumar, P., and, Sivapalan, M.: Climate, soil and vegetation controls on the temporal variability of vadose zone transport, Water Resour. Res., 47, W00J13, https://doi.org/10.1029/2010WR010194, 2011.

Harman, C. and Troch, P. A.: What makes Darwinian hydrology "Darwinian"? Asking a different kind of question about landscapes, Hydrol. Earth Syst. Sci., 18, 417-433, https://doi.org/10.5194/hess-18-417-2014, 2014.

Harman, C. J., Lohse, K. A., Troch, P. A., and Sivapalan, M.: Spatial patterns of vegetation, soils and microtopography from terrestrial laser scanning on two semi-arid hillslopes of contrasting lithology, J. Geophys. Res.-Biogeosci., 119, 163-180, https://doi.org/10.1002/2013JG002507, 2014.

Harte, J.: Toward a synthesis of the Newtonian and Darwinian worldviews, Phys. Today, 55, 29-34, 2002.

Hassanizadeh, S. M. and Gray, W. G.: General conservation equations for multiphase systems: 1. Averaging procedure, Adv. Water Resour., 2, 131-144, 1979. 
Hassanizadeh, S. M., Celia, M. A., and Dahle, H. K.: Dynamic effects in the capillary pressure-saturation relationship and their impacts on unsaturated flow, Vadose Z. J., 1, 38-57, 2002.

Hewlett, J. D. and Hibbert, A. R.: Factors affecting the response of small watersheds to precipitation in humid regions, in: Forest Hydrology, edited by: Sopper, W. E. and Lull, H. W., Pergamon Press, Oxford, 275-290, 1967.

Hipsey, M. R., Hamilton, D. P., Hanson, P. C., Carey, C. C., Coletti, J. Z., Read, J. S., Ibelings, B. W., Valesini, F. J., and Brookes, J. D.: Predicting the resilience and recovery of aquatic systems: A framework for model evolution within environmental observatories, Water Resour. Res., 51, 7023-7043, https://doi.org/10.1002/2015WR017175, 2015.

Horton, R. E.: The role of infiltration in the hydrologic cycle, Trans. Amer. Geophys. Union, 14, 446-460, 1933.

Hrachowitz, M., Savenije, H. H. G., Blöschl, G., McDonnell, J. J., Sivapalan, M., Pomeroy, J. W., Arheimer, B., Blume, T., Clark, M. P., Ehret, U., Fenicia, F., Freer, J. E., Gelfan, A., Gupta, H. V., Hughes, D. A., Hut, R. W., Montanari, A., Pande, S., Tetzlaff, D., Troch, P. A., Uhlenbrook, S., Wagener, T., Winsemius, H. C., Woods, R. A., Zehe, E., and Cudennec, C.: A decade of Predictions in Ungauged Basins (PUB) - a review, Hydrol. Sci. J., 58, 1-58, https://doi.org/10.1080/02626667.2013.803183, 2013.

Hrachowitz, M. and Clark, M. P.: HESS Opinions: The complementary merits of competing modelling philosophies in hydrology, Hydrol. Earth Syst. Sci., 21, 3953-3973, https://doi.org/10.5194/hess-21-3953-2017, 2017.

IACWD (Interagency Advisory Committee on Water Data): Guidelines for determining flood-flow frequency: Bulletin 17B of the Hydrology Subcommittee, Office of Water Data Coordination, U.S. Geological Survey, Reston, VA, 183 pp., available at: http: //water.usgs.gov/osw/bulletin17b/bulletin_17B.html (last access: 1 March 2018), 1982.

Jakeman, A. J. and Hornberger, G. M.: How much complexity is warranted in a rainfall-runoff model?, Water Resour. Res., 29, 2637-2649, 1993.

Jothityangkoon, C., Sivapalan, M., and Farmer, D.: Process controls of water balance variability in a large semi-arid catchment: Downward approach to hydrological model development, J. Hydrol., 254, 174-198, 2001.

Jothityangkoon, C. and Sivapalan, M.: Framework for exploration of climatic and landscape controls on catchment water balance, with emphasis on inter-annual variability, J. Hydrol., 371, 154168, https://doi.org/10.1016/j.jhydrol.2009.03.030, 2009.

Kandasamy, J., Sounthararajah, D., Sivabalan, P., Chanan, A., Vigneswaran, S., and Sivapalan, M.: Socio-hydrologic drivers of the pendulum swing between agriculture development and environmental health: A case study from Murrumbidgee river basin, Australia, Hydrol. Earth Syst. Sci., 18, 1027-1041, https://doi.org/10.5194/hess-18-1027-2014, 2014.

Kirchner, J. W.: Catchments as simple dynamical systems: Catchment characterization, rainfall-runoff modeling, and doing hydrology backward, Water Resour. Res., 45, W02429, https://doi.org/10.1029/2008WR006912, 2009.

Kleidon, A. and Renner, M.: Thermodynamic limits of hydrologic cycling within the Earth system: concepts, estimates and implications, Hydrol. Earth Syst. Sci., 17, 2873-2892, https://doi.org/10.5194/hess-17-2873-2013, 2013.
Klemeš, V.: Conceptualization and scale in hydrology, J. Hydrol., 65, 1-23, 1983.

Klemeš, V.: Dilettantism in Hydrology: Transition or Destiny?, Water Resour. Res., 22, 177S-188S, 1986.

Klemeš, V.: A hydrological perspective, J. Hydrol., 100, 3-28, 1988.

Kollet, S. J. and Maxwell, R. M.: Capturing the influence of groundwater dynamics on land surface processes using an integrated, distributed watershed model, Water Resour. Res., 44, W02402, https://doi.org/10.1029/2007WR006004, 2008.

Konar, M., Evans, T. P., Levy, M., Scott, C. A., Troy, T. J., Vörösmarty, C. J., and Sivapalan, M.: Water sustainability in a globalizing world: who uses the water?, Hydrol. Process., 30, 3330 3336, https://doi.org/10.1002/hyp.10843, 2016.

Kuil, L., Carr, G., Viglione, A., Prskawetz, A., and Blöschl, G.: Conceptualizing socio-hydrological drought processes: The case of the Maya collapse, Water Resour. Res., 52, 6222-6242, https://doi.org/10.1002/2015WR018298, 2016.

Kumar, M., Duffy, C. J., and Salvage, K. M.: A second-order accurate, finite volume-based integrated hydrologic modeling framework (FIHM) for simulation of surface and subsurface flow, Vadose Z. J., https://doi.org/10.2136/vzj2009.0014, 2009.

Lall, U.: Debates - The future of hydrological sciences: A (common) path forward? One water. One world. Many climes. Many souls, Water Resour. Res., 50, 5335-5341, https://doi.org/10.1002/2014WR015402, 2014.

Larsen, J. E., Sivapalan, M., Coles, N. A., and Linnet, P. E.: Similarity analysis of runoff generation processes in real-world catchments, Water Resour. Res., 30, 1641-1652, 1994.

Lee, H., Zehe, E., and Sivapalan, M.: Predictions of rainfall-runoff response and soil moisture dynamics in a microscale catchment using the CREW model, Hydrol. Earth Syst. Sci., 11, 819-849, https://doi.org/10.5194/hess-11-819-2007, 2007.

Levin, S. A.: The problem of pattern and scale in ecology, Ecology, 73, 1943-1967, 1992.

Li, H.-Y., Sivapalan, M., and Tian, F.: A comparative diagnostic analysis of runoff generation mechanisms in Oklahoma DMIP2 basins: The Blue River and the Illinois River, J. Hydrol., 418419, 90-109, 2012.

Li, H.-Y., Sivapalan, M., Tian, F., and Harman, C. J.: Functional approach to exploring climatic and landscape controls on runoff generation. 1. Behavioral constraints on runoff volume. Water Resour. Res., 50, 9300-9322, https://doi.org/10.1002/2014WR016307, 2014.

Liu, Y., Tian, F., Hu, H., and Sivapalan, M.: Socio-hydrologic perspectives of the co-evolution of humans and water in the Tarim River Basin, Western China: the Taiji-Tire Model, Hydrol. Earth Syst. Sci., 18, 1289-1303, https://doi.org/10.5194/hess-18-12892014, 2014.

Linsley, R. K., Kohler, M. A., and Paulhus, J. L. H.: Hydrology for Engineers, McGraw-Hill, New York, 340 pp., 1958.

Loritz, R., Hassler, S. K., Jackisch, C., Allroggen, N., van Schaik, L., Wienhöfer, J., and Zehe, E.: Picturing and modeling catchments by representative hillslopes, Hydrol. Earth Syst. Sci., 21, 1225-1249, https://doi.org/10.5194/hess-21-1225-2017, 2017.

Loucks, D. P., Van Beek, E., Stedinger, J. R., Dijkman, J. P., and Villars, M. T.: Water Resources Systems Planning and Management: An Introduction to Methods, Models and Applications, $680 \mathrm{pp}$., UNESCO, Paris, 2015. 
Lotka, A.: Natural selection as a physical principle, P. Natl. Acad. Sci. USA, 8, 151-154, 1922.

Lu, H., Moran, C. J., and Sivapalan, M.: A theoretical exploration of catchment-scale sediment delivery, Water Resour. Res., 41, W09415, https://doi.org/10.1029/2005WR004018, 2005.

L'vovich, M. I.: World Water Resources and Their Future, 415 pp., AGU, Washington, D.C., 1979.

Manabe, S.: Climate and the ocean circulation. 1. The atmospheric circulation and the hydrology of the earth's surface, Mon. Weather Rev., 97, 739-774, 1969.

Maxwell, R. M., Condon, L. E., and Kollet, S. J.: A high-resolution simulation of groundwater and surface water over most of the continental US with the integrated hydrologic model ParFlow v3, Geosci. Model Dev., 8, 923-937, https://doi.org/10.5194/gmd-8923-2015, 2015.

McDonnell, J. J.: A rationale for old water discharge through macropores in a steep, humid catchment, Water Resour. Res., 26, 2821-2832, 1990.

McDonnell, J. J., Sivapalan, M., Vaché, K., Dunn, S., Grant, G., Haggerty, R., Hinz, C., Hooper, R. P., Kirchner, J. W., Roderick, M. L., Selker, J., and Weiler, M.: Moving beyond heterogeneity and process complexity: A new vision for watershed hydrology, Water Resour. Res., 43, W07301, https://doi.org/10.1029/2006WR005467, 2007.

McGrath, G. S., Hinz, C., and Sivapalan, M. The effect of rainfall regional variability on rapid pesticide risk leaching potential, $\mathrm{J}$. Contam. Hydrol., 113, 56-65, 2010.

Mein, R. G. and Larson, C. L.: Modeling infiltration during steady rain, Water Resour. Res., 9, 384-394, 1973.

Milly, P. C. D., Betancourt, J., Falkenmark, M., Hirsch, R. M., Kundzewicz, Z. W., Lettenmaier, D. P., and Stouffer, R. J.: Stationarity is dead: Whither water management?, Science, 319, 573-574, https://doi.org/10.1126/science.1151915, 2008.

Minshall, N. E.: Predicting storm runoff on small experimental watersheds, Proc. Am. Soc. Civ. Eng., J. Hydraul. Div., 86, 17-38, 1960.

Mockus, V.: Estimation of total (and peak rates of) surface runoff for individual storms. Exhibit A in Appendix B, Interim Survey Report (Neosho) River Watershed, Washington, DC: Agricultural Research Service, United States Department of Agriculture, 61 pp., 1949.

Odling-Smee, F. J., Laland, K. N., and Feldman, M. W.: Niche Construction: The Neglected Process in Evolution, Princeton University Press, Princeton, 476 pp., 2003.

Oleson, K. W., Lawrence, D. W., Bonan, G. B., Drewniak, B., Huang, M., Koven, C. D., Levis, S., Li, F., Riley, W. J., Subin, Z. M., Swenson, S. C., Thornton, P. E.: Technical Description of Version 4.5 of the Community Land Model (CLM). NCAR Technical Report, NCAR/TN-503+STR, 420 pp, doi:10.5065/D6RR1W7M, http://opensky.ucar.edu/islandora/ object/technotes\%3A515/datastream/PDF/view (last access: last access: 1 March 2018.), 2013.

Or, D., Lehmann, P., and Assouline, S.: Natural length scales define the range of applicability of the Richards equation for capillary flows, Water Resour. Res., 51, 7130-7144, https://doi.org/10.1002/2015WR017034, 2015.

Pande, S. and Sivapalan, M.: Progress in socio-hydrology: a metaanalysis of challenges and opportunities, WIREs Water, 4, e1193, https://doi.org/10.1002/wat2.1193, 2017.
Patil, S., Sivapalan, M., Hassan, M. A., Ye, S., Harman, C. J., and Xu, X.: A network model for prediction and diagnosis of sediment dynamics at the watershed scale, J. Geophys. Res.-Earth Surf., 117, F00A04, https://doi.org/10.1029/2012JF002400, 2012.

Peters-Lidard, C. D., Clark, M., Samaniego, L., Verhoest, N. E. C., van Emmerik, T., Uijlenhoet, R., Achieng, K., Franz, T. E., and Woods, R.: Scaling, similarity, and the fourth paradigm for hydrology, Hydrol. Earth Syst. Sci., 21, 3701-3713, https://doi.org/10.5194/hess-21-3701-2017, 2017.

Platt, J. R.: Strong inference, Science, 146, 347-353, 1964.

Reggiani, P.: A Unifying Framework for Watershed Thermodynamics, PhD Dissertation, Centre for Water Research, Univ. West. Aust., 238 pp., 1999.

Reggiani, P., Sivapalan, M., and Hassanizadeh, S. M.: A unifying framework for watershed thermodynamics: Balance equations for mass, momentum, energy, entropy and the 2nd law of thermodynamics, Adv. Water Resour., 22, 367-398, 1998.

Reggiani, P., Hassanizadeh, S. M., Sivapalan, M., and Gray, W. G.: A unifying framework for watershed thermodynamics. Constitutive relationships. Adv. Water Resour., 23, 15-39, 1999.

Rippl, W.: The capacity of storage reservoirs for water supply, Minutes, Proc. Inst. Civil Eng., 71, 270-278, 1883.

Robinson, J. S., Sivapalan, M., and Snell, J. D.: On the relative roles of hillslope processes, channel routing and network geomorphology in the hydrological response of natural catchments, Water Resour. Res., 31, 3089-3101, 1995.

Robinson, J. S. and Sivapalan, M.: Temporal scales and hydrological regimes: Implications for flood frequency scaling, Water Resour. Res., 33, 2981-2999, 1997.

Robinson, T. M., La Pierre, K. J., Vadeboncoeur, M. A., Byrne, K. M., Thomey, M. L., and Colby, S. E.: Seasonal, not annual precipitation drives community productivity across ecosystems, Oikos, 122, 727-738, https://doi.org/10.1111/j.16000706.2012.20655.x, 2012.

Roderick, M. L. and Farquhar, G. D.: The pan evaporation paradox, in: Global Change and the Earth System: A Planet Under Pressure, Steffen, W., Sanderson, A., Tyson, P., Jäger, J., Matson, P., Moore III, B., Oldfield, F., Richardson, K., Schellnhuber, H.-J., Turner II, B. L., and Wasson, R., Springer-Verlag, p. 167, 2004.

Rodriguez-Iturbe, I. and Valdes, J. B.: The geomorphologic structure of hydrologic response, Water Resour. Res., 15, 1409-1420, 1979.

Rodriguez-Iturbe, I.: Ecohydrology: A hydrologic perspective of climate-soil-vegetation dynamics, Water Resour. Res., 36, 3-9, 2000.

Saco, P. M. and Moreno-de las Heras, M.: Ecogeomorphic coevolution of semiarid hillslopes: Emergence of banded and striped vegetation patterns through interaction of biotic and abiotic processes, Water Resour. Res., 49, 115-126, https://doi.org/10.1029/2012WR012001, 2013.

Sanderson, M. R., Bergtold, J. S., Heier Stamm, J. L., Caldas, M. M., and Ramsey, S. M.: Bringing the "social" into sociohydrology: Conservation policy support in the Central Great Plains of Kansas, USA, Water Resour. Res., 53, 6725-6743, https://doi.org/10.1002/2017WR020659, 2017.

Savenije, H. H. G.: Opinion paper: Linking Darcy's equation to the linear reservoir, Hydrol. Earth Syst. Sci. Discuss., https://doi.org/10.5194/hess-2017-580, in review, 2017. 
Savenije, H. H. G. and Hrachowitz, M.: HESS Opinions "Catchments as meta-organisms - a new blueprint for hydrological modelling", Hydrol. Earth Syst. Sci., 21, 1107-1116, https://doi.org/10.5194/hess-21-1107-2017, 2017.

Schaefli, B., Harman, C. J., Sivapalan, M., and Schymanski, S. J.: HESS Opinions: Hydrologic predictions in a changing environment: behavioral modeling, Hydrol. Earth Syst. Sci., 15, 635646, https://doi.org/10.5194/hess-15-635-2011, 2011.

Schymanski, S. J.: Transpiration as the Leak in the Carbon Factory: A Model of Self-Optimising Vegetation, PhD Dissertation, Sch. Env. Syst. Eng., Univ. of West. Aust., Perth, 244 pp., 2007.

Schymanski, S. J., Sivapalan, M., Roderick, M. L., Hutley, L., and Beringer, J.: An optimality-based model of the dynamic feedbacks between natural vegetation and the water balance, Water Resour. Res., 45, W01412, https://doi.org/10.1029/2008WR006841, 2009.

Scott, C. A.: The water-energy-climate nexus: resources and policy outlook for aquifers in Mexico, Water Resour. Res., 47, W00L04, https://doi.org/10.1029/2011WR010805, 2011.

Senatore, A., Mendicino, G., Gochis, D. J., Yu, W., Yates, D. N., and Kunstmann, H.: Fully coupled atmosphere-hydrology simulations for the central Mediterranean: Impact of enhanced hydrological parameterization for short and long time scales, J. Adv. Model. Earth Syst., 7, 1693-1715, https://doi.org/10.1002/2015MS000510, 2015.

Shen, C. and Phanikumar, M. S.: A process-based, distributed hydrologic model based on a large-scale method for surfacesubsurface coupling, Adv. Water Resour., 33, 1524-1541, https://doi.org/10.1016/j.advwatres.2009.07.001, 2010.

Silberstein, R. P., Held, A., Hatton, T. J., Viney, N. R., and Sivapalan, M.: Energy balance of a natural jarrah (Eucalyptus marginata) forest in Western Australia. Measurements in spring and summer, Agric. Forest Meteorol., 109, 79-104, 2001.

Sivapalan, M., Jeevaraj, C. G., and Viney, N. R.: Catchment-scale water balance modeling to predict the effects of land use changes in forested catchments. 1. Small catchment water balance model, Hydrol. Process., 10, 393-411, 1996.

Sivapalan, M.: Process complexity at hillslope scale, process simplicity at the watershed scale: Is there a connection?, Hydrol. Process., 17, 1037-1041, https://doi.org/10.1002/hyp.5109, 2003.

Sivapalan, M., Blöschl, G., Zhang, L., and Vertessy, R.: Downward approach to hydrological prediction, Hydrol. Process., 17, 21012111, https://doi.org/10.1002/hyp.1425, 2003.

Sivapalan, M., Takeuchi, K., Franks, S. W., Gupta, V. K., Karambiri, H., Lakshmi, V., Liang, X., McDonnell, J. J., Mendiondo, E. M., O'Connell, P. E., Oki, T., Pomeroy, J. W., Schertzer, D., Uhlenbrook, S., and Zehe, E.: IAHS Decade on Predictions in Ungauged Basins (PUB), 2003-2012: Shaping an exciting future for the hydrological sciences, Hydrol. Sci. J., 48, 857-880, 2003.

Sivapalan, M.: Pattern, Process and Function: Elements of a New Unified Hydrologic Theory at the Catchment Scale, Contribution to: Encyclopaedia of Hydrologic Sciences, edited by: Anderson, M. G., 13, 193-219, John Wiley \& Sons, 2005.

Sivapalan, M. and Young, P. C.: Downward approach to hydrological model development, in: Encyclopaedia of Hydrologic Sciences, edited by: Anderson, M. G., 134, 2081-2098, John Wiley \& Sons, 2005.
Sivapalan, M. The secret to "doing better hydrological science": Change the question!, Hydrol. Process., 23, 1391-1396, https://doi.org/10.1002/hyp.7242, 2009.

Sivapalan, M., Savenije, H. H. G., and Blöschl, G.: Sociohydrology: A new science of people and water, Hydrol. Process., 26, 1270-1276, https://doi.org/10.1002/hyp.8426, 2012.

Sivapalan, M., Konar, M., Srinivasan, V., Chhatre, A., Wutich, A., Scott, C. A., Wescoat, J. L., and RodriguezIturbe, I.: Socio-hydrology: Use-inspired water sustainability science for the Anthropocene, Earth's Future, 2, 225-230, https://doi.org/10.1002/2013EF000164, 2014.

Sivapalan, M.: Debates - Perspectives in Socio-hydrology: Changing water systems and the "tyranny of small problems" - Socio-hydrology, Water Resour. Res., 51, 4795-4805, https://doi.org/10.1002/2015WR017080, 2015.

Sivapalan, M. and Blöschl, G.: Time scale interactions and the coevolution of humans and water, Water Resour. Res., 51, 69887022, https://doi.org/10.1002/2015WR017896, 2015.

Sivapalan, M. and Blöschl, G.: The growth of hydrological understanding: Technologies, ideas and societal needs shape the field, Water Resour. Res., 53, 8137-8146 https://doi.org/10.1002/2017WR021396, 2017.

Smith, J. A.: Representation of basin scale in flood peak distributions, Water Resour. Res., 28, 2993-2999, 1992.

Srinivasan, V., Sanderson, M., Garcia, M., Konar, M., Blöschl, G., and Sivapalan, M.: Prediction in a sociohydrological world, Hydrol. Sci. J., 62, 338-345, https://doi.org/10.1080/02626667.2016.1253844, 2017.

Stephenson, G. R. and Freeze, R. A.: Mathematical simulation of subsurface flow contributions to snowmelt runoff, Reynolds Creek Watershed, Idaho, Water Resour. Res., 10, 284-294, 1974.

Stephenson, N. L.: Climatic control of vegetation distribution: The role of the water balance, Am. Nat., 135, 649-670, 1990.

Stokes, D. E.: Pasteur's Quadrant: Basic Science and Technological Innovation, Brookings Institution Press, Washington, D.C., 1997.

Sugawara, M.: The flood forecasting by a series storage type model, Proc. Int. Symp. on Floods and their Computation, Leningrad, USSR, 1-6, 1967.

Thomas, H. A.: Improved methods for national water assessment, water resource contract WR15249270, USGS unnumbered series, Harvard Water Resources Group, available at: http://pubs. er.usgs.gov/publication/70046351 (last access: 1 March 2018), 1981.

Thompson, S. E., Harman, C. J., Konings, A. G., Sivapalan, M., and Troch, P. A.: Comparative hydrology across Ameriflux sites: The variable roles of climate, vegetation and groundwater, Water Resour. Res., 47, W00J07, https://doi.org/10.1029/2010WR009797, 2011a.

Thompson, S. E., Harman, C. J., Troch, P. A., Brooks, P. D., and Sivapalan, M.: Scaling of ecohydrologically mediated water balance partitioning: A synthesis framework for catchment ecohydrology, Water Resour. Res., 47, W00J03, https://doi.org/10.1029/2010WR009998, 2011b.

Thompson, S. E., Sivapalan, M., Harman, C. J., Srinivasan, V., Hipsey, M., Reed, P., Montanari, A., and Blöschl, G.: Developing predictive insight into changing water systems: use-inspired hydrologic science for the Anthropocene, Hydrol. Earth Syst. Sci., 17, 5013-5039, https://doi.org/10.5194/hess-17-5013-2013, 2013. 
Tian, F., Hu, H., Lei, Z., and Sivapalan, M.: Extension of the Representative Elementary Watershed approach for cold regions via explicit treatment of energy related processes, Hydrol. Earth Syst. Sci., 10, 619-644, https://doi.org/10.5194/hess-10619-2006, 2006.

Tian, F., Li, H.-Y., and Sivapalan, M.: Model diagnostic analysis of seasonal switching of runoff generation mechanisms in the Blue River basin, Oklahoma, J. Hydrol., 418-419, 136-149, 2012.

Troch, P. A., Martinez, G. F., Pauwels, V. R. N., Durcik, M., Sivapalan, M., Harman, C. J., Brooks, P. D., Gupta, H. V., and Huxman, T. E.: Climate and vegetation water-use efficiency at catchment scales. Hydrol. Process., 23, 2409-2414, https://doi.org/10.1002/hyp.7358, 2009.

Vörösmarty, C. J., Green, P., Salisbury, J., and Lammers, R. B.: Global water resources: Vulnerability from climate change and population growth, Science, 289, 284-288, 2000.

Wagener, T., Sivapalan, M., Troch, P. A., and Woods, R. A.: Catchment classification and hydrologic similarity, Geog. Compass, 1, 901-931, https://doi.org/10.1111/j.1749-8198.2007.00039.x, 2007.

Wagener, T., Sivapalan, M., Troch, P. A., McGlynn, B. L., Harman, C. J., Gupta, H. V., Kumar, P., Rao, P. S. C., Basu, N. B., and Wilson, J. S.: The future of hydrology: An evolving science for a changing world, Water Resour. Res., 46, W05301, https://doi.org/10.1029/2009WR008906, 2010,

Wang, D. and Tang, Y.: A one-parameter Budyko model for water balance captures emergent behavior in Darwinian hydrologic models, Geophys. Res. Lett., 41, 4569-4577, https://doi.org/10.1002/2014GL060509, 2014.

Wang, D., Zhao, J., Tang, Y., and Sivapalan, M.: A thermodynamic interpretation of Budyko and L'vovich formulations of annual water balance: proportionality hypothesis and maximum entropy production, Water Resour. Res., 51, 3007-3016, https://doi.org/10.1002/2014WR016857, 2015.

Weingartner, R. and Aschwanden, H.: Discharge regime-the basis for the estimation of average flows, in: Hydrological Atlas of Switzerland, Map 5.2, Swiss Federal Office for the Environment, Bern, Switzerland, 1992.

Westerberg, I. K., Di Baldassarre, G., Beven, K. J., Coxon, G., and Krueger, T.: Perceptual models of uncertainty for sociohydrological systems: a flood risk change example, Hydrol. Sci. J., 62, 1705-1713, doi10.1080/02626667.2017.1356926, 2017.

Westhoff, M., Zehe, E., Archambeau, P., and Dewals, B.: Does the Budyko curve reflect a maximum-power state of hydrological systems? A backward analysis, Hydrol. Earth Syst. Sci., 20, 479486, https://doi.org/10.5194/hess-20-479-2016, 2016.

Wing, O. E. J., Bates, P. D., Sampson, C. C., Smith, A. M., Johnson, K. A., and Erickson, T. A.: Validation of a $30 \mathrm{~m}$ resolution flood hazard model of the conterminous United States, Water Resour. Res., 53, 7968-7986, https://doi.org/10.1002/2017WR020917, 2017.

Wittenberg, H. and Sivapalan, M.: Watershed groundwater balance estimation using streamflow recession analysis and baseflow separation, J. Hydrol., 219, 20-33, 1999.

Wood, E. F., Sivapalan, M., Beven, K. J., and Band, L. E.: Effects of spatial variability and scale with implications to hydrologic modeling, J. Hydrol., 102, 29-47, 1988.

Wood, E. F., Roundy, J. K., Troy, T. J., van Beek, R., Bierkens, M. F. P., Blyth, E. M., de Roo, A., Döll, P., Ek, M., Famiglietti, J.
S., Gochis, D., van de Giesen, N., Houser, P., Jaffe, P., Kollet, S., Lehner, B., Lettenmaier, D. P., Peters-Lidard, C., Sivapalan, M., Sheffield, J., Wade, A., and Whitehead, P.: Hyper-resolution global land surface modeling: Meeting a grand challenge for monitoring Earth's terrestrial water, Water Resour. Res., 47, W05301, https://doi.org/10.1029/2010WR010090, 2011.

Wood, E. F., Roundy, J. K., Troy, T. J., van Beek, R., Bierkens, M. F. P., Blyth, E. M., de Roo, A., Döll, P., Ek, M., Famiglietti, J. S., Gochis, D., van de Giesen, N., Houser, P., Jaffe, P., Kollet, S., Lehner, B., Lettenmaier, D. P., Peters-Lidard, C., Sivapalan, M., Sheffield, J., Wade, A., and Whitehead, P.: Reply to comment by Keith J. Beven and Hannah L. Cloke on "Hyper-resolution global land surface modeling: Meeting a grand challenge for monitoring Earth's terrestrial water", Water Resour. Res., 48, W01802, https://doi.org/10.1029/2011WR011202, 2012.

Woods, R. A., Sivapalan, M., and Duncan, M. J.: Investigating the Representative Elementary Area concept - An approach based on field data, Hydrol. Process., 9, 291-312, 1995.

Woolhiser, D. A.: Hydrologic and watershed modeling - state of the art, Trans. Amer. Soc. Agric. Engrs., 16, 553-559, 1973.

Yang, Y., Donohue, R. J., and McVicar, T. R.: Global estimation of effective plant rooting depth: Implications for hydrological modeling, Water Resour. Res., 52, 8260-8276, https://doi.org/10.1002/2016WR019392, 2016.

Ye, S., Covino, T. P., Sivapalan, M., Basu, N. B., Li, H.Y., and Wang, S.-W.: Dissolved nutrient retention dynamics in river networks: A modeling investigation of transient flows and scale effects, Water Resour. Res., 48, W00J17, https://doi.org/10.1029/2011WR010508, 2012.

Yevjevich, V.: Misconceptions in hydrology and their consequences, Water Resour. Res., 4, 225-232, 1968.

Young, P. C.: Top-down and data-based mechanistic modelling of rainfall-flow dynamics at the catchment scale, Hydrol. Process., 17, 2195-2217, https://doi.org/10.1002/hyp.1328, 2003.

Young, P. C. and Beven, K. J.: Data-based mechanistic modelling and the rainfall-flow nonlinearity, Environmetrics, 5, 335-363, 1994.

Zehe, E. and Sivapalan, M.: Threshold behaviour in hydrological systems as (human) geo-ecosystems: manifestations, controls, implications, Hydrol. Earth Syst. Sci., 13, 1273-1297, https://doi.org/10.5194/hess-13-1273-2009, 2009.

Zehe, E., Lee, H., and Sivapalan, M.: Dynamical process upscaling for deriving catchment scale state variables and constitutive relations for meso-scale process models, Hydrol. Earth Syst. Sci., 10, 981-996, https://doi.org/10.5194/hess-10-981-2006, 2006.

Zehe, E., Ehret, U., Pfister, L., Blume, T., Schröder, B., Westhoff, M., Jackisch, C., Schymanski, S. J., Weiler, M., Schulz, K., Allroggen, N., Tronicke, J., van Schaik, L., Dietrich, P, Scherer, U., Eccard, J., Wulfmeyer, V., and Kleidon, A.: HESS Opinions: From response units to functional units: a thermodynamic reinterpretation of the HRU concept to link spatial organization and functioning of intermediate scale catchments, Hydrol. Earth Syst. Sci., 18, 4635-4655, https://doi.org/10.5194/hess-18-4635-2014, 2014.

Zhang, Z., Tian, F., and Sivapalan, M.: Groundwater dynamics under water saving irrigation and implications for sustainable water management in an oasis: Tarim River Basin, China, Hydrol. Earth Syst. Sci., 18, 3951-3967, https://doi.org/10.5194/hess-183951-2014, 2014. 